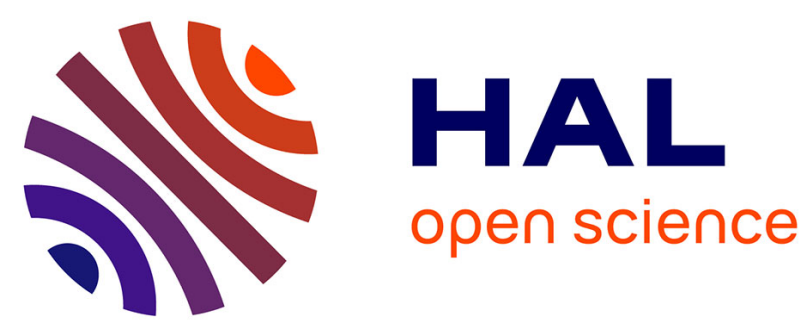

\title{
Experimental Investigation of Allotropic Transformation of Cobalt: Influence of Temperature Cycle, Mechanical Loading and Starting Microstructure
}

Nadjib Iskounen, Pierre-Antoine Dubos, Jamal Fajoui, Michel Coret, Marie-José Moya, Baptiste Girault, Nicolas Barrier, Nicolas Bruzy, Eric Hug, David Gloaguen

\section{To cite this version:}

Nadjib Iskounen, Pierre-Antoine Dubos, Jamal Fajoui, Michel Coret, Marie-José Moya, et al.. Experimental Investigation of Allotropic Transformation of Cobalt: Influence of Temperature Cycle, Mechanical Loading and Starting Microstructure. Metallurgical and Materials Transactions A, 2021, 52, pp.1477-1491. 10.1007/s11661-021-06142-7 . hal-03408430

\author{
HAL Id: hal-03408430 \\ https://hal.science/hal-03408430
}

Submitted on 29 Oct 2021

HAL is a multi-disciplinary open access archive for the deposit and dissemination of scientific research documents, whether they are published or not. The documents may come from teaching and research institutions in France or abroad, or from public or private research centers.
L'archive ouverte pluridisciplinaire $\mathbf{H A L}$, est destinée au dépôt et à la diffusion de documents scientifiques de niveau recherche, publiés ou non, émanant des établissements d'enseignement et de recherche français ou étrangers, des laboratoires publics ou privés. 


\section{Experimental investigation of allotropic transformation of cobalt: influence of}

Nadjib ISKOUNEN ${ }^{\mathrm{a}}$, Pierre-Antoine DUBOS ${ }^{\mathrm{a}}$, Jamal FAJOUI ${ }^{\mathrm{a}}$, Michel CORET ${ }^{\mathrm{a}}$, Marie-José MOYA ${ }^{\mathrm{a}}$, Baptiste GIRAULT ${ }^{\mathrm{a}}$, Nicolas BARRIER ${ }^{\mathrm{b}}$, Nicolas BRUZY ${ }^{\mathrm{a}}$, Eric HUG $^{\mathrm{b}}$, David GLOAGUEN ${ }^{\mathrm{a}}$

7

8 a Université de Nantes - Centrale Nantes, Institut de Recherche en Génie Civil et 9 Mécanique (UMR CNRS 6183), 58 rue Michel Ange - BP 420, 44606 Saint-Nazaire 10 Cedex, France

$11{ }^{\mathrm{b}}$ UNICAEN, Laboratoire de Cristallographie et Sciences des Matériaux (UMR CNRS 12 6508), 6 boulevard Maréchal Juin, 14050 Caen, France

14 *Corresponding author: pierre-antoine.dubos@univ-nantes.fr

16 Graphical abstract: Evolution of metastable cobalt FCC volume proportion during 17 thermal cycle and mechanical loading.

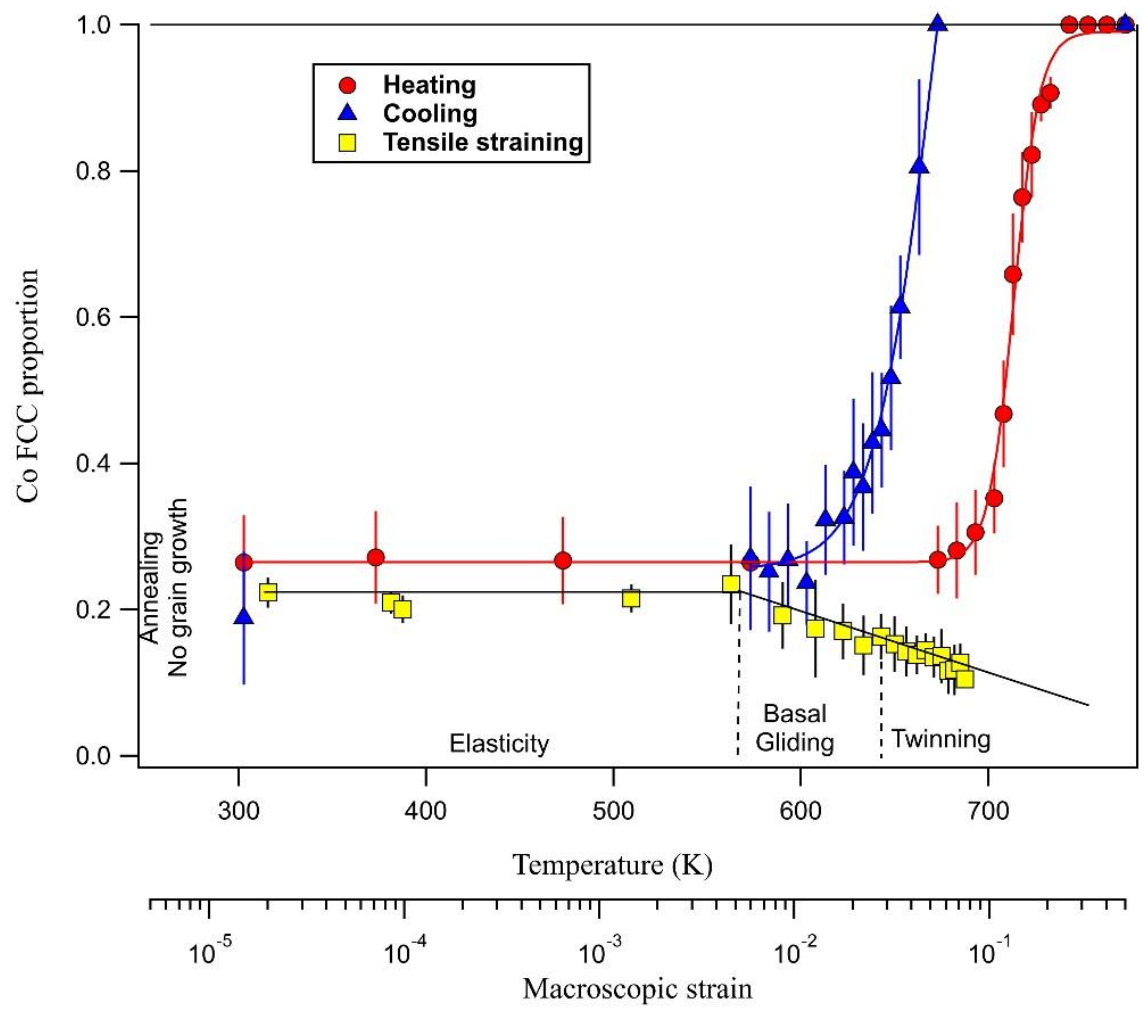


19 Abstract:

20 The allotropic phase transformation in polycrystalline high-purity cobalt is incompletely

21 reversible and exhibits a temperature hysteresis. This leads to the presence of a FCC

22 metastable phase at room temperature, which alters the mechanical properties. Moreover

23 this phase transformation seems to be able to be induced by the plastic deformation. The

24 influence of thermal cycling and initial microstructure on the phase transformation has

25 been analyzed with different experimental approaches namely in situ X-ray diffraction,

26 differential scanning calorimetry and high temperature digital image correlation analysis.

27 A multiscale analysis, under an in situ tensile test, has been adopted to follow the phase

28 transformation induced by the plastic deformation. The main result shows that the

29 transformation is initiated by basal slip mechanisms, in competition with twinning

30 mechanisms during the second work-hardening stage.

32 Keywords:

33 Cobalt, allotropic transformation, X-ray diffraction, plastic strain, crystallographic 34 texture, in situ testing.

\section{Introduction}

37 Mechanical properties of metallic materials such as high-purity cobalt, are directly link

38 to the crystallographic phase structures and microstructure defects presence. The

39 mechanical behavior of two-phase cobalt remains unclear, when phase distribution and 
40 evolution are not controlled. Results of the literature exhibited an important improvement

41 of the mechanical properties of cobalt when it presents a two-phase structure [1].

High-purity polycrystalline cobalt exhibits an allotropic transformation (reversible and diffusionless) from HCP (Hexagonal Close-Packed) phase to FCC (Face Centered-Cubic) on around $713 \mathrm{~K}$ (austenitic transformation). The reverse transformation, from FCC to $\mathrm{HCP}$ phase (named martensitic transformation [2-4]), occurs roughly at $603 \mathrm{~K}$. The cobalt transformations lead to a temperature hysteresis which depends on the number of applied thermal transformation cycles [4,5].

Most of the time, cobalt martensitic transformation remains incomplete. Consequently, a residual FCC phase persists at room temperature in association with the predominant HCP 50 phase $[3,6,7]$.

Sanderson [7] investigated the tensile properties of polycrystalline cobalt at room temperature so as to get the HCP phase stable, using different initial retained FCC phase volume proportions, grain sizes and purity samples. He found that the retained FCC phase

54 volume fraction of polycrystalline cobalt, at room temperature, depends on the thermal history, the purity and the grain size. Marx et al. [8] studied by X-Ray Diffraction (XRD) the strain-induced phase transformation, at room temperature, in a $2 \mu \mathrm{m}$ thick film deposited on polyimide substrate, using in situ tensile tests. They have shown that the untransformed metastable FCC phase was reduced from $51 \%$ down to $8 \%$ when the total macroscopic strain increases from $2 \%$ up to $8 \%$.

60 Martinez et al. [9] investigated the dislocation microstructure of deformed polycrystalline

61 cobalt by analyzing the different modes responsible for plastic strain. They have observed two distinct work hardening stages: a stage A, up to $4 \%$ of plastic strain, where basal

63 dislocation glide is the main deformation mechanism, and a stage $\mathrm{B}$, where plastic 
64 deformation is mostly accommodated by twinning mechanisms, in agreement with Seeger et al. [10]. These different deformation stages were also observed by Fleurier et al. [11]. HCP cold rolled metals tend to exhibit a specific deformation texture, called basal texture. A principal $\{00.1\}$ basal texture component was indeed observed in polycrystalline rolled cobalt by Electron Back Scatter Diffraction (EBSD) [3,9]. The phase transformation in high-purity cobalt occurs by the glide of dislocations, due to the shear stress, on the habit $\{111\}_{\mathrm{FCC}} / /\{00.1\}_{\mathrm{HCP}}$ planes [12]. Hesemann et al. $[13,14]$ studied the influence of the texture on martensitic transformation in cobalt thin films, by varying the habit plane inclination angle from film surface, at different temperatures using in situ synchrotron XRD. They have observed that the phase transformation depends on the inclination angle between $\{111\}_{\mathrm{FCC}} / /\{00.1\}_{\mathrm{HCP}}$ planes and the film surface, this transformation arising more easily at intermediary inclination of about $20^{\circ}$.

The present study focuses on the understanding of the allotropic transformation of polycrystalline high-purity cobalt, which might be affected by the initial microstructure as well as the thermal and mechanical loadings, using several characterization techniques. After a detailed description of the experimental methods, allotropic transformation behavior during thermal cycle, such as the evolution of the FCC phase volume proportion using in situ XRD laboratory technique, is presented. Moreover, the influence of the number of applied thermal cycles on the energetic parameters, carried out by Differential

83 Scanning Calorimetry (DSC), is reported. On the other hand, an overview of the effect of the initial microstructure (modulated thanks to various annealing treatments) on the phase transformation is given. Finally, the strain effect on the phase transformation at room temperature is presented. In situ tensile tests under XRD have been used to study the

87 influence of the strain hardening mechanisms onto the phase transformations. 
91 Commercial polycrystalline cobalt sheets (Goodfellow Company) of high-purity (99.9

92 wt. \%), cold-rolled to $0.5 \mathrm{~mm}$ in thickness, and with a recrystallized state, were used for

93 the present study.

94 Metallographic examinations of the as-received material have revealed that the average

95 grain size is about $24 \mu \mathrm{m}$, with a standard deviation of $12 \mu \mathrm{m}$. It appears that the initial 96 microstructure displays two sets of grain shape corresponding to the two phases (HCP 97 and FCC). Fig. 1 shows a predominant polygonal grain family population, corresponding 98 to the HCP phase, and a rather limited number of triangular and plate geometries for the 99 FCC phase.

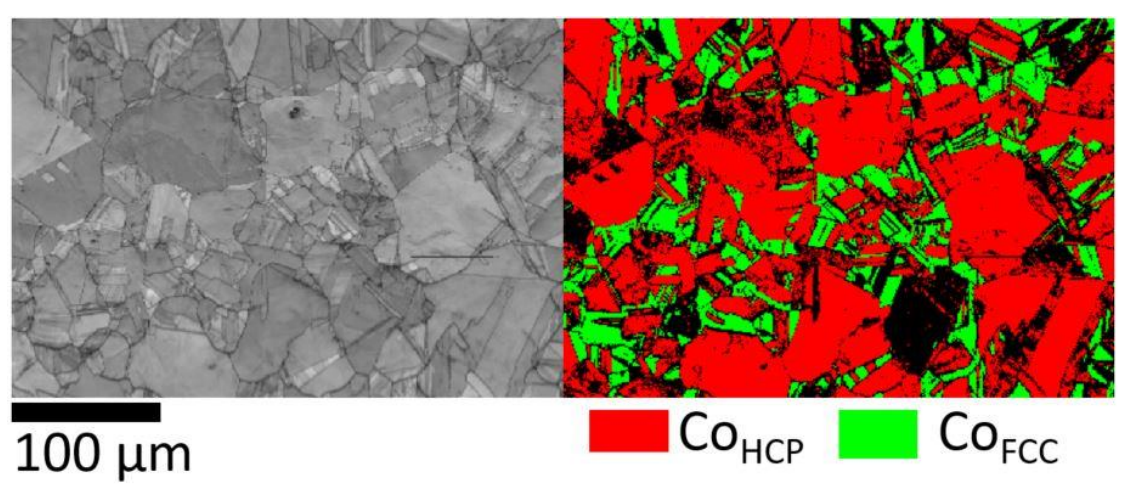

101 Figure 1: EBSD Image Quality (IQ) map and phase cartography of as-received cobalt 102 microstructure.

103

104 Initial crystallographic textures and retained FCC phase ratio, at room temperature, were determined by XRD technique. A four-circle Seifert XRD3003 PTS diffractometer 
equipped with an Euler cradle, a Position Sensitive Detector (PSD) with a $2 \theta$ effective

107 windows of $8.6^{\circ}$, a $1 \mathrm{~mm}$ diameter collimator and an IDS camera (in order to align the

108 sample in the center of the goniometer), was used. A $\mathrm{Cr}$ anode ( $\mathrm{CrK}_{\alpha 1+2}$ radiation), 109 operating at $30 \mathrm{kV}$ and $35 \mathrm{~mA}$, was used (wavelength $\lambda=2.28964 \AA$ ). The $\mathrm{K}_{\beta}$ component

110 of the Cr radiation was eliminated using a vanadium filter installed in front of the detector.

111 Using $\theta-2 \theta$ scanning mode, the diffraction spectra were recorded from $60^{\circ}$ to $106^{\circ}$ in $2 \theta$

112 with a step size of $0.05^{\circ}$ and a counting time of $126 \mathrm{~s} / \mathrm{step}$. The analyzed reflections are

113 listed in Table 1. The initial averaged FCC phase volume proportion, obtained according

114 to the method described in the section 2.4 .3 , is about $22 \%$.

115 The crystallographic textures were determined from the Orientation Distribution

116 Functions (ODF) calculated by the WIMV method implemented in the BEARTEX

117 software [15], and were obtained from experimental Pole Figures (PFs) $\{10.0\}_{\mathrm{HCP}}$,

$118\{00.2\}_{\mathrm{HCP}},\{10.1\}_{\mathrm{HCP},}\{10.2\}_{\mathrm{HCP},}\{111\}_{\mathrm{FCC}}$ and $\{200\}_{\mathrm{FCC}}$ with average error coefficients

119 in the order of 0.08 , except for the initial FCC phase $(0.2)$. The declination $(\psi)$ and

120 azimuthal $(\varphi)$ angles varied from 0 to $65^{\circ}\left(\Delta \psi=5^{\circ}\right)$ and from 0 to $355^{\circ}\left(\Delta \varphi=5^{\circ}\right)$,

121 respectively. At $\varphi=0^{\circ}$ and $\psi=90^{\circ}$, the scattering vector was aligned with the Rolling

122 Direction (RD).

$124 \quad$ 2.2. Thermal cycles and Differential Scanning Calorimetry

125 The influence of the initial microstructure (grain size and retained FCC proportion) on 126 the phase transformation was studied using DSC. First of all, cobalt samples were 127 annealed at a temperature set between $573 \mathrm{~K}$ and $1273 \mathrm{~K}$ for $1 \mathrm{~h}$, and cooled down with 
128 a cooling rate of $40 \mathrm{~K} / \mathrm{min}$. In a second step, DSC scanning was performed on four 129 samples (as-received and annealed at 573,673 and $773 \mathrm{~K}$ ) with a heating path up to $773 \mathrm{~K}$

130 then down to $593 \mathrm{~K}$ (heating and cooling rate $=10 \mathrm{~K} / \mathrm{min}$ ) according to the methodology

131 described by Ray and Smith [2], in order to measure the $\mathrm{HCP} \rightarrow$ FCC and FCC $\rightarrow$ HCP

132 transformation temperatures. Ray and Smith [2] showed that the austenitic transformation

133 temperature increases with higher heating rates. A phase quantification was carried out at

$134743 \mathrm{~K}$ with the same selected rate to ensure that the transformation was complete.

\section{2.3. Macroscopic dilatometric test}

136 Dilatometric tests have been performed using a homemade device on dog bone shaped

137 tensile specimens $[16,17]$. The samples were machined by electroerosion along the rolling

138 direction. The gage section is $5 \mathrm{~mm}$ in length, $5 \mathrm{~mm}$ in width and $0.5 \mathrm{~mm}$ in thickness.

139 The sample is placed into a testing box under a low pressure of Argon and heated by Joule

140 effect. A 2-color pyrometer (SensorTherm METIS M322) measures the temperature at

141 the center of the specimen starting from $300^{\circ} \mathrm{C}$, due to its intrinsic emissivity. Based on

142 an alumina-based paint, a speckle pattern is deposited on the surface of the sample with

143 a fine nozzle airbrush. During the test, a high-resolution camera (Prosilica GT6600 : 6576

$144 \times 4384 \mathrm{px}^{2}$ ) records images of a $9 \times 6 \mathrm{~mm}^{2}$ area. Macroscopic total strain field is then

145 computed using Digital Image Correlation method (VIC software). The images and

146 temperature values are recorded simultaneously, a establish the dilatometric curve (total

147 strain versus temperature) ean finally be obtained.

$149 \quad$ 2.4. In situ X-ray diffraction measurements 
151 In situ experiments have been carried out in order to study the influence of the temperature

152 on the phase transformation behavior. The variation of phase (FCC and HCP) ratio during

153 heating and cooling was evaluated by XRD technique on Bruker D8 advance

154 diffractometer operating at $40 \mathrm{kV}$ and $40 \mathrm{~mA}$, equipped with a primary germanium (111)

155 Johansson monochromator $\left(\lambda \mathrm{K}_{\alpha 1}=1.5406 \AA\right)$ and a Lynxeye detector. The XRD patterns

156 were recorded in the $2 \theta$ angular range $35-95^{\circ}$ with a step size of $0.015^{\circ}$ and a counting

157 time of $0.9 \mathrm{~s} / \mathrm{step}$. The thermal cycle (with a rate of $0.5 \mathrm{~K} / \mathrm{s}$ ) was conducted between 303

158 and $773 \mathrm{~K}$. Despite the short counting time, the signal-to-noise ratios are only slightly

159 affected and the quality of the fitting shows, on average over all the peaks, an error of

$1600.0011^{\circ}$ for the position and less than $5 \%$ for the integrated intensities. The listed

161 diffraction peaks presented in Table 1 were monitored for each temperature of the

162 thermal cycle described in Table 2. The temperature ranges and the heating step have

163 been chosen around the temperatures of austenitic and martensitic transformations.

164 
165 Table 1: XRD reflections tracked for each experiment and the plane family couples used 166 for the phase volume fraction calculations.

\begin{tabular}{|c|c|c|c|}
\hline & \multicolumn{3}{|c|}{ Studies } \\
\hline & $\begin{array}{c}\text { Strain influence on } \\
\text { phase transformation }\end{array}$ & $\begin{array}{l}\text { Texture } \\
\text { analysis }\end{array}$ & $\begin{array}{c}\text { Thermal cycle influence on } \\
\text { phase transformation }\end{array}$ \\
\hline $\begin{array}{c}\text { HCP } \\
\text { plane } \\
\text { families }\end{array}$ & $\multicolumn{2}{|c|}{10.0},\{00.2\},\{10.1\}$ and $\{10.2\}$ & $\begin{array}{c}\{10.0\},\{00.2\},\{10.1\},\{10.3\} \\
\text { and }\{10.2\}\end{array}$ \\
\hline $\begin{array}{c}\text { FCC } \\
\text { plane } \\
\text { families }\end{array}$ & \multicolumn{3}{|c|}{111} and $\{200\}$ \\
\hline $\begin{array}{l}\text { Planes } \\
\text { family } \\
\text { couples }\end{array}$ & \multicolumn{2}{|c|}{$\begin{array}{l}\{10.0\}_{\mathrm{HCP}} /\{111\}_{\mathrm{FCC}}, \\
\{10.0\}_{\mathrm{HCP}} /\{200\}_{\mathrm{FCC}} \\
\{00.2\}_{\mathrm{HCP}} /\{111\}_{\mathrm{FCC}} \\
\{00.2\}_{\mathrm{HCP}} /\{200\}_{\mathrm{FCC}} \\
\{10.1\}_{\mathrm{HCP}} /\{111\}_{\mathrm{FCC}} \\
\{10.1\}_{\mathrm{HCP}} /\{200\}_{\mathrm{FCC}}, \\
\{10.2\}_{\mathrm{HCP}} /\{111\}_{\mathrm{FCC}} \\
\{10.2\}_{\mathrm{HCP}} /\{200\}_{\mathrm{FCC}}\end{array}$} & $\begin{array}{l}\{10.0\}_{\mathrm{HCP}} /\{111\}_{\mathrm{FCC}}, \\
\{10.0\}_{\mathrm{HCP}} /\{200\}_{\mathrm{FCC}} \\
\{00.2\}_{\mathrm{HCP}} /\{111\}_{\mathrm{FCC}} \\
\{00.2\}_{\mathrm{HCP}} /\{200\}_{\mathrm{FCC}} \\
\{10.1\}_{\mathrm{HCP}} /\{111\}_{\mathrm{FCC}} \\
\{10.1\}_{\mathrm{HCP}} /\{200\}_{\mathrm{FCC}} \\
\{10.3\}_{\mathrm{HCP}} /\{111\}_{\mathrm{FCC}} \\
\{10.3\}_{\mathrm{HCP}} /\{200\}_{\mathrm{FCC}} \\
\{10.2\}_{\mathrm{HCP}} /\{111\}_{\mathrm{FCC}} \\
\{10.2\}_{\mathrm{HCP}} /\{200\}_{\mathrm{FCC}}\end{array}$ \\
\hline
\end{tabular}

167 
169 Table 2: Applied temperatures for in situ XRD experiments during thermal cycle

170 (heating rate $0.5 \mathrm{~K} / \mathrm{s}$ between each temperature step - $1 \mathrm{~h}$ acquisition duration for each

171 temperature).

172

\begin{tabular}{|c|c|c|}
\hline & Temperature range (K) & Temperature step (K) \\
\hline Initial & At 303 & - \\
\hline Heating & From 373 to 673 & 100 \\
\cline { 2 - 3 } & From 673 to 703 & 10 \\
\cline { 2 - 3 } & From 703 to 733 & 5 \\
\cline { 2 - 3 } & From 733 to 773 & 10 \\
\hline Cooling & From 773 to 673 & 100 \\
\cline { 2 - 3 } & From 673 to 653 & 10 \\
\cline { 2 - 3 } & From 653 to 623 & 5 \\
\cline { 2 - 3 } & From 623 to 573 & 10 \\
\hline Final & At 303 & - \\
\hline
\end{tabular}

\subsubsection{Tensile tests}

174 In situ uniaxial monotonic uniaxial tensile tests were carried out, at room temperature, to

175 study the influence of elastoplastic strain on the allotropic transformation. These

176 mechanical tests were performed on a DEBEN device, equipped with a load cell of $5 \mathrm{kN}$

177 capacity, and controlled by the displacement between clamping jaws. The dog bone

178 shaped tensile specimens were machined by electroerosion with a gage section of $26 \mathrm{~mm}$

179 in length, $7 \mathrm{~mm}$ in width and $0.5 \mathrm{~mm}$ in thickness in three different directions with respect

180 to RD: $0^{\circ} / \mathrm{RD}, 45 \% / \mathrm{RD}$ and $90^{\circ} / \mathrm{RD}$, latter corresponding thus to the Transverse Direction

181 (TD). In the same way, as explained in 2.3, the samples were also speckled and images

182 were recorded during the test. Digital Image Correlation have then been processed to 183 obtain the macroscopic total strain fields.

184 The samples were strained stepwise up to $7.8 \%$ with a strain rate of $0.2 \mathrm{~mm} / \mathrm{min}$. At each straining step, and after a stress relaxation of about 20 minutes to obtain stable mechanical

186 fields over the entire diffracting volume, the camera images were captured and the

$1872 \theta$ diffraction spectra were performed with an angle ranging from $60^{\circ}$ to $106^{\circ}$ with a step 
size of $0.05^{\circ}$ and a counting time of 126 s/step. The reflections listed in Table 1 were analyzed. The crystallographic texture was also determined after the in situ tensile

190 experiment as described in 2.1.

\subsubsection{Analysis method}

193 Experimental XRD peak profiles were fitted by a Pseudo-Voigt function which takes into

194 account the $\mathrm{K}_{\alpha 1}-\mathrm{K}_{\alpha 2}$ doublet [18]. For each diffraction peak, background was fitted 195 through a $2^{\text {nd }}$ order polynomial function. Before peak profile analysis, angular corrections

196 (Lorentz, polarization and absorption factors) are also applied [19].

197 The FCC phase volume fraction (denoted $\mathrm{f}^{\mathrm{FCC}}$ ) has been determined for each 198 measurement point using the equation (1) as formulated by Bonarski et al. [20]:

$199 \mathrm{f}^{\mathrm{FCC}}=\left(1+\frac{\mathrm{I}_{\mathrm{hkl}}^{\mathrm{HCP}}}{\mathrm{I}_{\mathrm{hkl}}^{\mathrm{FCC}}} \frac{\mathrm{R}_{\mathrm{hkl}}^{\mathrm{FCC}}}{\mathrm{R}_{\mathrm{hkl}}^{\mathrm{HCP}}}\right)^{-1}$

200 where $I_{h k 1}$ is the integrated intensity of the corresponding $\{h k l\}$ peak. $R_{h k l}$ is the reflectivity

201 of the lattice plane $\{h k l\}$, and is given by the following equation (2) introduced in the 202 literature [20]:

$203 \quad \mathrm{R}_{\mathrm{hkl}}=\frac{1}{\mathrm{v}^{2}}\left|\mathrm{~F}_{\mathrm{hkl}}\right|^{2}\left(\frac{1+\cos ^{2}(2 \theta)}{\sin ^{2}(2 \theta) \cos (\theta)}\right) \mathrm{m} \frac{\mathrm{e}^{-2 \mathrm{M}}}{\mu}$

204 where $v$ is the volume of the unit cell (in $\AA^{3}$ ), $F_{h k l}$ is the structure factor, $2 \theta$ is the 205 considered Bragg angle (in rad), $m$ is the $\{h k l\}$ planes multiplicity factor, $\mu$ is the linear 206 absorption coefficient (in $\mathrm{cm}^{-1}$ ) and $e^{-2 M}$ is the Debye-Waller factor [21,22]. 
207 The volume fraction of the phases was calculated from several groups of family planes,

208 as presented in Table1, to obtain the average FCC phase distribution and evaluate the

209 influence of the texture on the quantitative phase analysis.

\section{3. Results and discussion}

\section{3.1. Allotropic transformation characterization during thermal cycle}

\section{3.1.1. Phase proportion evolution and typical temperatures}

213 In order to characterize the $\mathrm{HCP} \leftrightarrow \mathrm{FCC}$ transformation behavior, the evolution of the

214 integrated diffraction peak intensity for each reflection corresponding to the HCP and

215 FCC phases were recorded as a function of the temperature. An example is given in Fig.

2162 for $\{111\}_{\text {FCC }}$ and $\{00.2\}_{\text {HCP }}$ reflections during heating and cooling. The volume fraction

217 of the phases can be determined according to the equations (1) and (2).
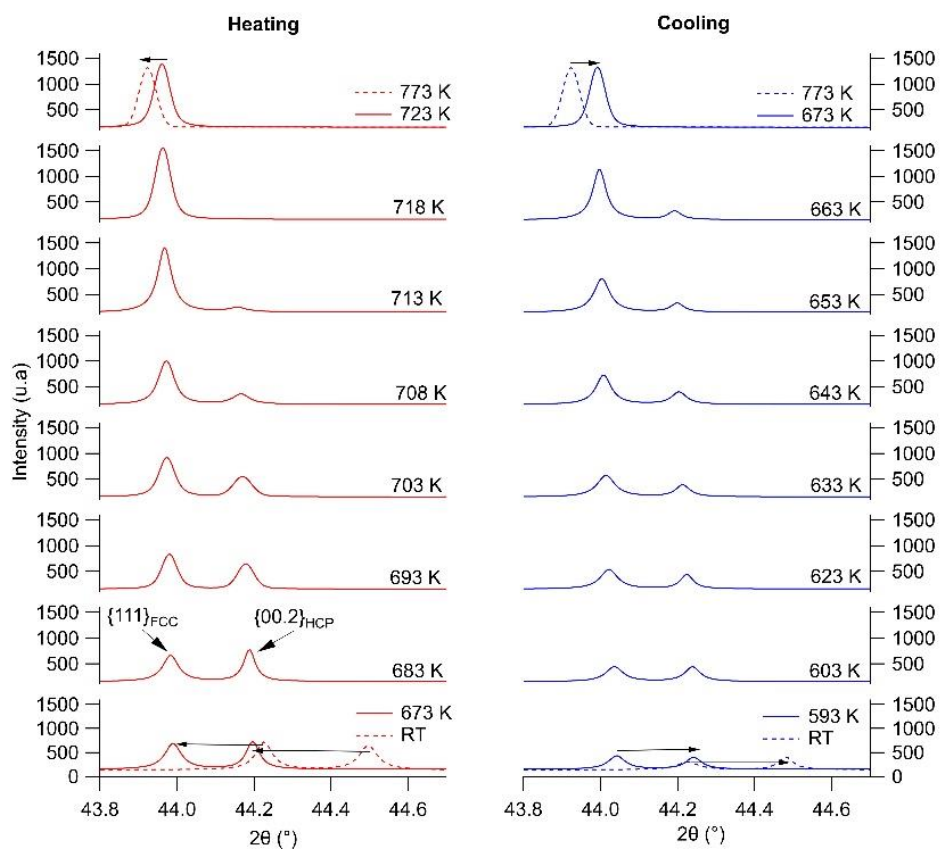

219 Figure 2: Diffraction patterns for $\{111\}_{\mathrm{FCC}}$ and $\{00.2\}_{\mathrm{HCP}}$ reflections during heating and 220 cooling. 
222 Fig. 3 gives FCC phase proportion evolution during the thermal cycle described in

223 Table 2. During heating, the HCP $\rightarrow$ FCC transformation begins at the austenitic start

224 temperature denoted $A_{s}=673 \mathrm{~K}$ and ends at the austenitic finish temperature named

$225 \mathrm{~A}_{\mathrm{f}}=743 \mathrm{~K}$. During cooling, the reverse transformation FCC $\rightarrow$ HCP arises at the

226 martensitic start temperature $\mathrm{M}_{\mathrm{s}}=673 \mathrm{~K}$ and comes back to its original state when the

227 martensitic finish temperature of $\mathrm{M}_{\mathrm{f}}=593 \mathrm{~K}$ is reached. The two experimental curves

228 can be fitted by sigmoidal laws which allow to define the transformation temperatures

$229 T_{H C P-F C C}$ and $T_{F C C-H C P}$. These temperatures are determined when the FCC proportion has

230 a relative variation of $50 \%$ over the temperature cycle, knowing that the initial proportion

231 is $26 \%$ and that the transformation is complete during heating. With this methodology,

$232 T_{H C P-F C C}=714 \mathrm{~K}$ and $T_{F C C-H C P}=653 \mathrm{~K}$ are obtained, revealing a temperature hysteresis

233 around $60 \mathrm{~K}$. One can notice that the diffraction patterns have also enabled to identify

$234 \mathrm{CoO}$ and $\mathrm{Co}_{3} \mathrm{O}_{4}$ oxides formation from $673 \mathrm{~K}$ that persist when cooling down to room

235 temperature. It is important to point out that the presence of a thin oxide layer does not

236 affect the quantification of the HCP and FCC phase proportions. Finally, it seems that the

237 phase transformation is faster during heating than during cooling. This can be related to

238 the phase transformation mechanism which is based on dislocation movements [23],

239 themselves favored by an increase in temperature. 


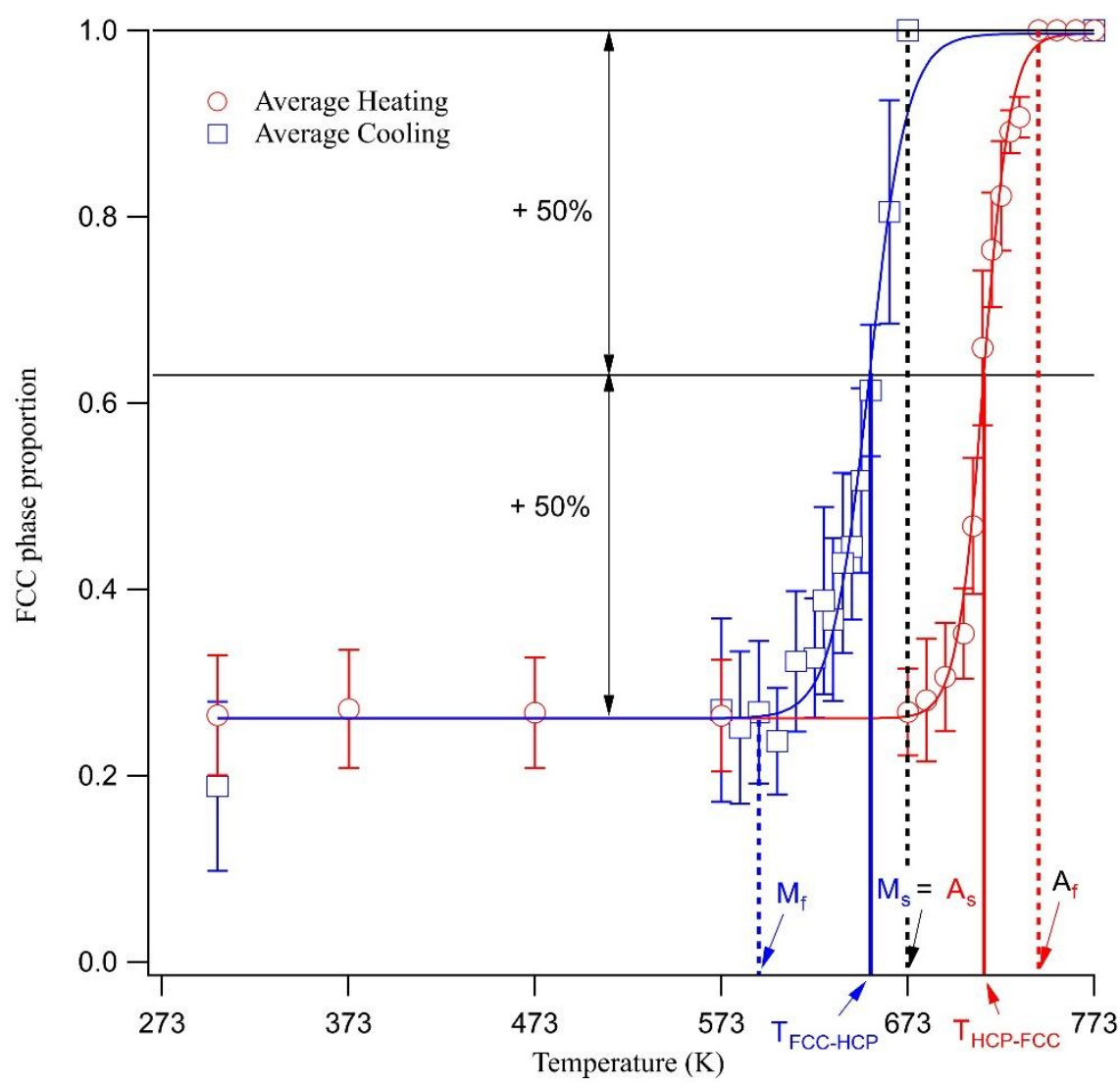

241 Figure 3: Volume fraction of FCC phase during heating (red circle) and cooling (blue 242 square) of cobalt calculated from XRD data. Error bars are the standard deviation on the 2438 couples of family planes.

\subsubsection{Lattice strain measurements during the thermal cycle}

246 Lattice strain of each $\{$ hkl $\}$ plane family can be determined considering lattice spacing

$247\left(d_{h k l}\right)$ as an elastic strain gage using the following equation [24]:

$248\langle\varepsilon(h k l)\rangle_{V_{d}}=\ln \left(\frac{\left\langle d^{h k l}\right\rangle_{V_{d}}}{d_{0}^{h k l}}\right)=\ln \left(\frac{\sin \theta_{0}(h k l)}{\langle\sin \theta(h k l)\rangle_{V_{d}}}\right)$

$249\langle\varepsilon(h k l)\rangle_{V_{d}}$ is the elastic lattice strain. \langle\rangle$_{V_{d}}$ indicates an averaging over diffracting grains

250 for the considered $\{\mathrm{hkl}\}$ reflection. For a given $\{\mathrm{hkl}\}$ reflection, $d_{0}^{h k l}$ and $\theta_{0}(h k l)$ are the

251 interplanar spacing and the diffraction angle (Bragg angle), respectively, in the 
undeformed sample i.e. prior to any thermal or mechanical loading. Fig. 4(a) gives the evolution of the lattice strains observed for different $\{h k l\}$ reflection of the two phases during the applied thermal cycle. This evolution is linear for both heating and cooling, enabling to estimate the Coefficients of Thermal Expansion (CTE) $\alpha_{h k l}$ for each plane family within the analyzed polycrystal. The obtained values are represented in Fig. 4(b) and are in agreement with the literature [21]. Matsumoto [4] has also shown that the CTE of HCP single crystal is substantially affected by the orientation of the $c$-axis within the sample coordinate system. Thermal cycle induces a large strain, the largest one actually reaches more than $8000 \mu$-strain $\left(\times 10^{-6} \mathrm{~mm} / \mathrm{mm}\right)$ for the $\{00.2\}_{\mathrm{HCP}}$ set of grains. The main thermal dilatation occurs then along the [00.2] $]_{\mathrm{HCP}}$ direction. During cooling, plastic deformations are induced and can be explained by the presence of residual lattice strains. These results agree with prior investigations on high-purity cobalt showing slipping lines

264 due to plastic deformation during the thermal cycle $[23,25]$.

265 Fig. 4(c) shows the residual lattice strains present after the thermal cycle for each analyzed reflection. Initially, residual strains can be considered negligible due to the annealed character of the as-received materials. This allows considering the initial state of samples as a strain-free reference. After the thermal cycle, residual lattice strains have slightly increased, especially for $\{00.2\}_{\mathrm{HCP}},\{10.2\}_{\mathrm{HCP}}$ and $\{200\}_{\mathrm{FCC}}$ reflections.

270 Regarding uncertainties, only $\{00.2\}_{\mathrm{HCP}}$ planes present an unambiguous residual strain of 271 a few hundred of $\mu$-strains in tension. As shown in Fig. 4, these residual strains measured

272 after a thermal cycle are related to the phase transformation and its associated volume variation as well as the accommodation related to the thermal and plastic anisotropies. 


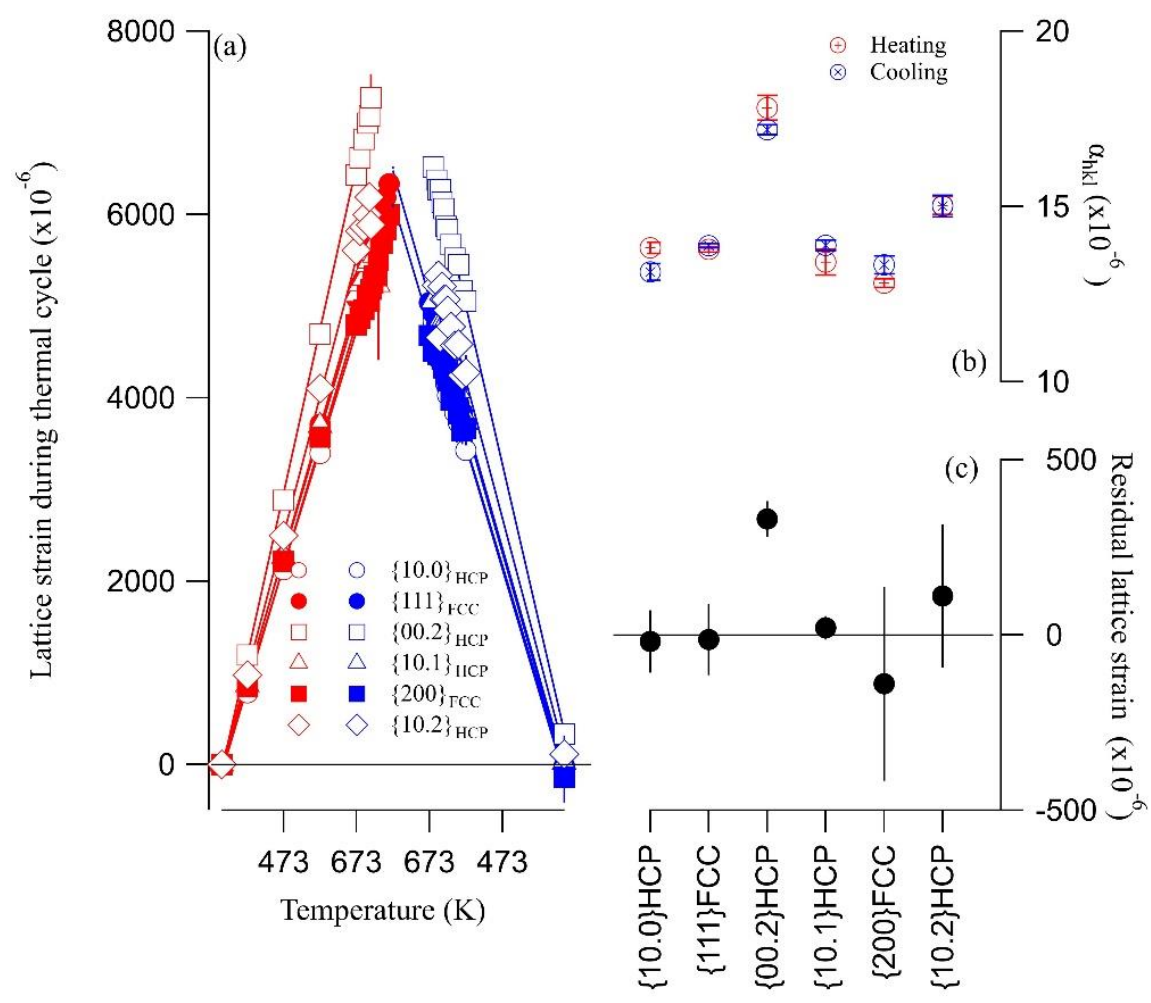

274

275 Figure 4: Mechanical state during thermal cycle considering the different tracked plane 276 families. (a) Lattice strain evolution during heating (red) and cooling (blue). (b) Thermal 277 expansion coefficients during heating (red open circle) and cooling (blue open circle) 278 obtained from XRD results. (c) Measured residual lattice strains after (black solid circle) 279 the thermal cycle.

\subsubsection{Macroscopic thermal dilatation}

282 The post-treatment of image correlation results enables to access to $\varepsilon_{\mathrm{xx}}$ (parallel to RD), $\varepsilon_{\mathrm{yy}}$ (parallel to the transverse direction (TD)) and $\gamma_{\mathrm{xy}}$ strain components. Fig. 5 shows the dilatometric curves obtained by coupling the temperatures measured by pyrometer (at the center of the sample) and the strain fields obtained by image correlation method. The

286 phase transformation induces a change of volume, due to the change of the lattice

287 structures, of about $0.3 \%$ in the case of high-purity polycrystalline cobalt, as reported in the literature $[12,25,26]$. Hence, in the temperature range between $573 \mathrm{~K}$ and $773 \mathrm{~K}$, the 
289 dilatometric curve is the consequence of the competition between thermal expansion and

290 volumetric change. As it can be seen, both dilatometric curves along x and y display a

291 temperature hysteresis caused by the phase transformation, which is not observed on the

292 lattice strains during the thermal cycle (see Fig. 4(a)). The difference in the scale of

293 analysis may be the reason for these observations. XRD results exhibit the combination

294 of macroscopic (or Type-I) and intergranular strains (or Type-II) whereas dilatometry

295 only gives access to macroscopic strains. The hysteresis of $\varepsilon_{\mathrm{xx}}$ dilatometric curve is

296 qualitatively slightly broader than the one of $\varepsilon_{\mathrm{yy}}$ dilatometric curve and could be explained

297 by a slight anisotropy or texture effect. Moreover, hysteresis occurs systematically

298 between the temperatures $\mathrm{M}_{\mathrm{f}}=593 \mathrm{~K}$ and $\mathrm{A}_{\mathrm{f}}=743 \mathrm{~K}$. Beyond austenitic finish

299 temperature, $\mathrm{A}_{\mathrm{f}}$, the dilatometric curve displays a linear evolution (for both of $\varepsilon_{\mathrm{xx}}$ and $\varepsilon_{\mathrm{yy}}$ )

300 with temperature that matches a pure thermal expansion or contraction during heating or

301 cooling, respectively. $\varepsilon_{\mathrm{xx}}$ and $\varepsilon_{\mathrm{yy}}$ strain components exhibit a quasi equibiaxial strain state

302 with an order of magnitude similar to the measured lattice strains induced by the thermal

303 cycle (see Fig. 4). Finally, the dilatometric curve of $\gamma_{\mathrm{xy}}$ clearly highlights the absence of 304 macroscopic planar shearing during the thermal cycle. 

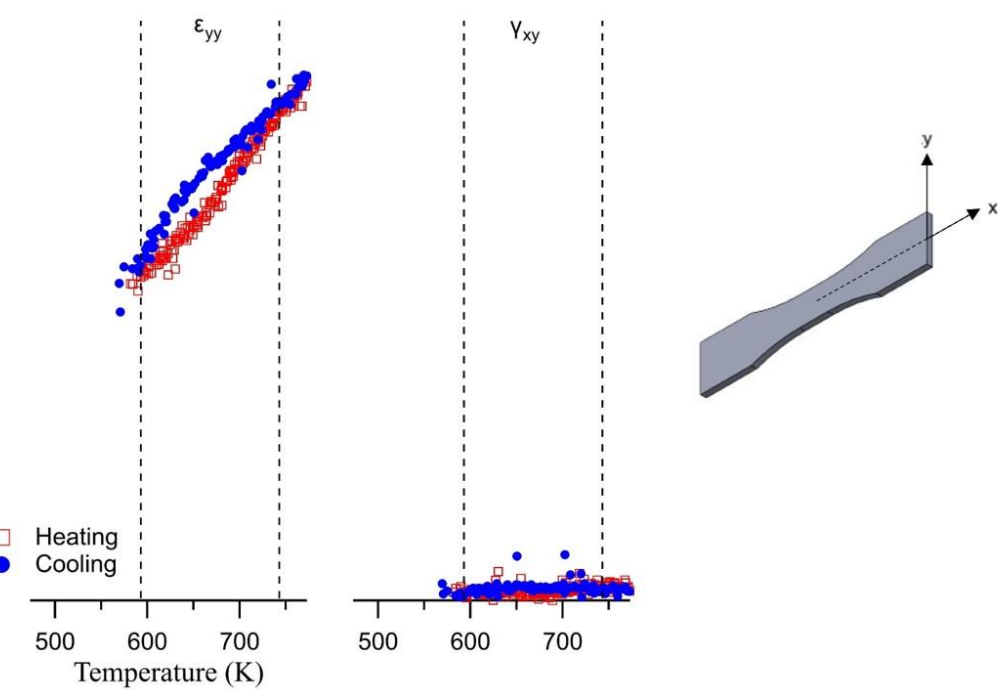

306 Figure 5: Dilatometric curves according to $\varepsilon_{\mathrm{xx}}, \varepsilon_{\mathrm{yy}}$ and $\gamma_{\mathrm{xy}}$ during the thermal cycle. (x 307 corresponds for this experiment to the rolling direction).

\subsubsection{Influence of initial microstructure on the allotropic transformation}

310 Fig. 6 shows the influence of annealing temperature on the grain size and on the volume

311 fraction of the retained FCC phase. In the present work, an annealing duration of one hour

312 has been chosen in order to have a limited granular growth so that grain size evolution

313 remains a minor contribution to the microstructure changes no matter the selected

314 annealing temperature. These results are then compared with previous works for a $1373 \mathrm{~K}$

315 annealing temperature with durations ranging from 1 to 96 hours [27]. The grain size,

316 deduced from metallographic observations, slightly increases with annealing temperature

317 but does not seem very significant as compared to the power type increase appearing from

31820 hours of heat treatment at $1373 \mathrm{~K}$. Concerning the proportion of retained FCC phase,

319 it exponentially decreases from $28 \%$ (as-received) down to almost $10 \%$ for $873 \mathrm{~K}$

320 annealing, in accordance with Sanderson [7]. For annealing temperatures greater than

$321873 \mathrm{~K}$ or longer annealing durations, this proportion remains constant. 
322 Overall, these results allow to explain the final FCC phase proportion met after the

323 thermal cycle. In fact, the thermal cycle applied during the previous in situ analysis was

324 including a heating stage until $773 \mathrm{~K}$. This treatment has induced a complete

325 transformation of the HCP phase and significantly reduced the proportion of residual FCC

326 phase at room temperature.

327 The results of Fig. 6 clearly show that annealing treatments at moderate temperature

328 ( $T_{\text {annealing }}<T_{H C P-F C C}$ ) enable to homogenize the microstructure with a reduction of the 329 retained FCC proportion combined with a limited grain growth. The energy required for

330 phase transformation is much lower than the one for grain growth, showing to some extent

331 the independence of these two phenomena.

(a)
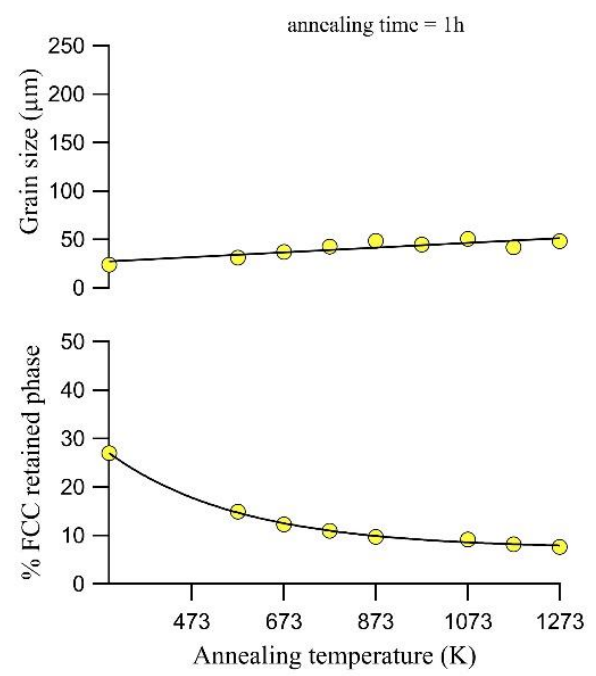

(b)

annealing temperature $=1373 \mathrm{~K}$
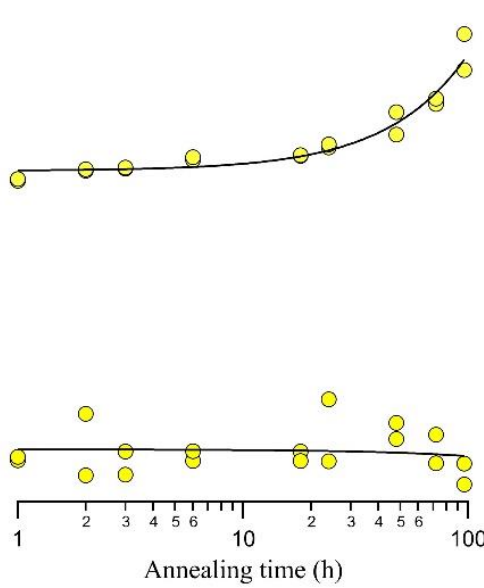

Figure 6: Influence of annealing conditions (temperature for a time of $1 \mathrm{~h}$ (a) and time for 335 a temperature of $1373^{\circ} \mathrm{K}(\mathrm{b})$ ) on grain size and retained FCC phase proportion evolution. 
The influence of initial microstructure (i.e. retained FCC phase ratio and grain size to a

338 lesser extent) on the phase transformation, performed using DSC, is plotted in Fig. 7.

339 Austenitic and martensitic transformation peaks are tracked during the DSC thermal

340 cycle, on the as-received Co specimen as well as on the $573 \mathrm{~K}, 673 \mathrm{~K}$ and $773 \mathrm{~K}$ annealed

341 samples with $40 \mathrm{~K} / \mathrm{min}$ cooling rate. The temperature of the $\mathrm{HCP} \rightarrow \mathrm{FCC}$ transformation

342 increases with annealing temperature. The results show that the temperature to initially

343 transform the HCP phase is directly related to the initial proportion of the retained FCC

344 phase: the higher the annealing temperature, the lower the retained FCC volume fraction

345 and the higher the $\mathrm{HCP} \rightarrow$ FCC phase transformation temperature. Indeed, austenitic

346 transformation needs more thermal energy to enable phase transformation as HCP volume

347 fraction to be transformed increases. In return, since the reverse transformation (i.e., FCC

$348 \rightarrow \mathrm{HCP}$ ) takes place during cooling with $100 \%$ FCC phase (austenitic transformation is

349 completely finished at $773 \mathrm{~K}$ ), the martensitic transformation temperature is then

350 unchanged during cooling.
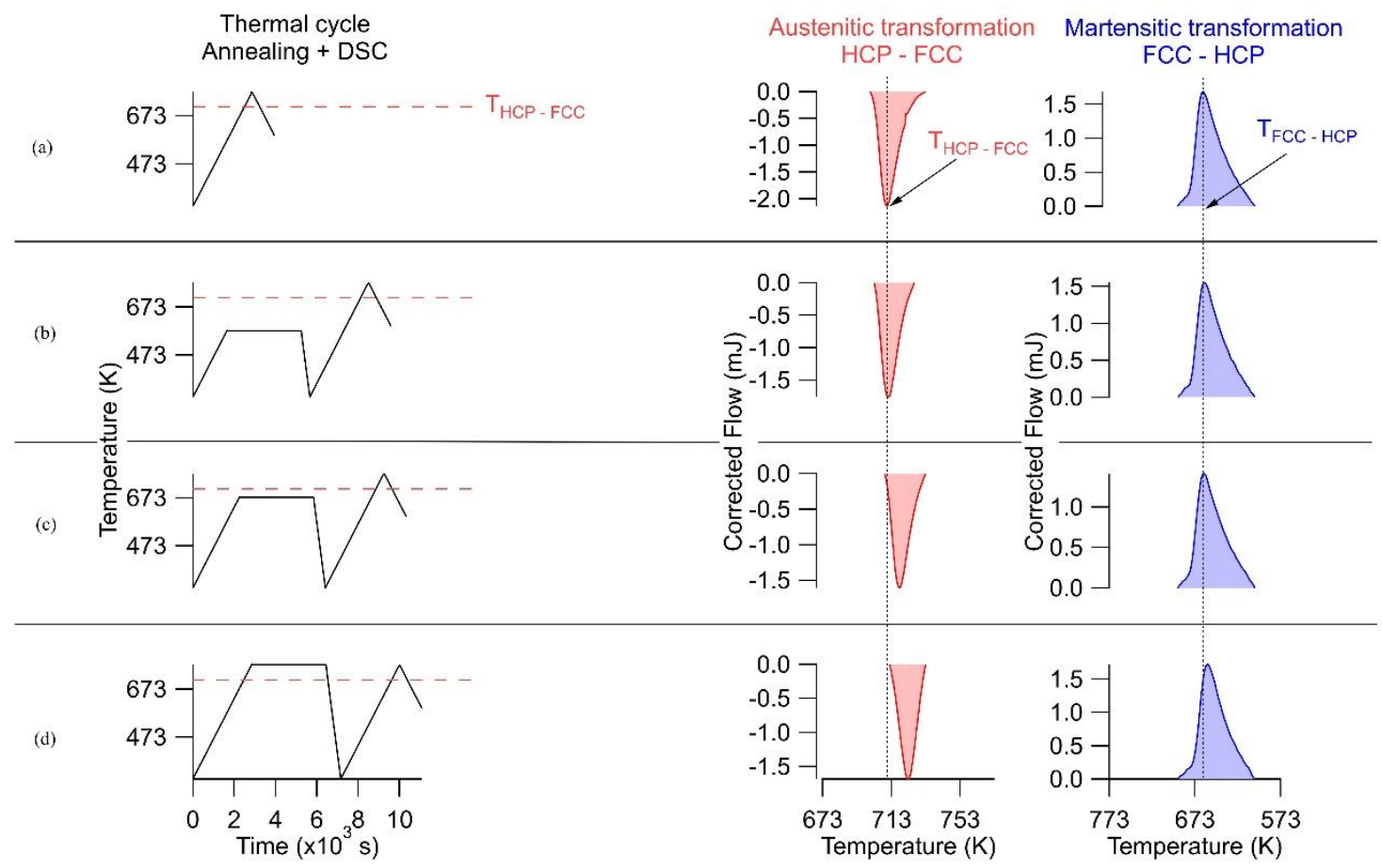
352 Figure 7: Thermal loading paths in DSC performed for as-received (a), $573 \mathrm{~K}$ (b), $673 \mathrm{~K}$ 353 (c) and $773 \mathrm{~K}$ (d) annealed samples with corresponding austenitic (red) and martensitic 354 (blue) transformation peak tracking.

356 Despite a microstructure that appears to be stable, when subjected to thermal cycles 357 around the transformation hysteresis $(593 \mathrm{~K}-773 \mathrm{~K})$, the sample annealed at $773 \mathrm{~K}$ 358 during one hour shows (see Fig. 8) an austenitic temperature which only becomes stable 359 after about 15 cycles. It could be noted that the austenitization temperatures of the as360 received sample and the two other annealed samples stabilize at the same value $(\approx 721 \mathrm{~K})$.

361 This observation shows that it is necessary to transform the material about fifteen times 362 in order to homogenize it and to make its temperature $T_{H C P-F C C}$ independent of the 363 following heat treatments. As displayed in Fig. 8, the martensitic transformation 364 temperature does not depend on the initial microstructure and therefore on annealing 365 temperature. This is convenient with the fact that it transforms the same FCC phase 366 proportion (i.e. $100 \%$ ). In the same way, this transformation is insensitive to the number 367 of thermal cycles as the $T_{F C C-H C P}$ temperature varies less than $2 \mathrm{~K}$. 


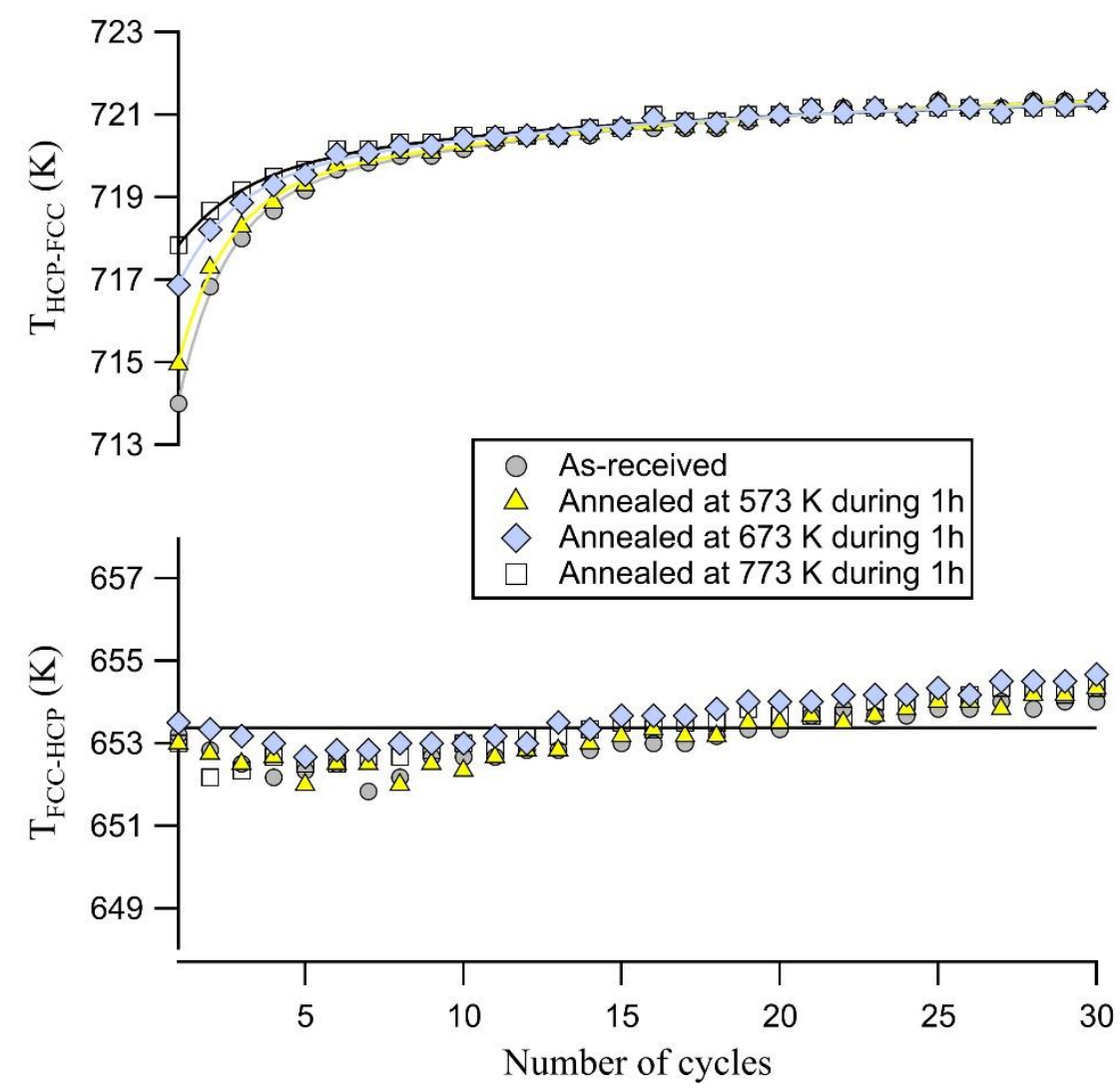

369 Figure 8: Temperatures of $\mathrm{HCP} \rightarrow \mathrm{FCC}$ and $\mathrm{FCC} \rightarrow \mathrm{HCP}$ transformations as a function 370 of the number of applied DSC cycles (up to 30 cycles) of as-received sample superposed 371 with the result of $573 \mathrm{~K}, 673 \mathrm{~K}$ and $773 \mathrm{~K}$ annealed samples.

372 Bauer et al. [23] showed a grain growth of 15 to $80 \mu \mathrm{m}$ with 60 DSC cycles, which does

373 not influence the stabilized transformation temperature after 15 cycles. An additional

374 study was carried out on samples with different grain sizes and the same FCC proportion

$375\left(\mathrm{~d}=100 \mu \mathrm{m}, \mathrm{f}_{\mathrm{FCC}}=0.1\right.$ for an annealed sample during 48 hours at $1373 \mathrm{~K}$ and $\mathrm{d}=25 \mu \mathrm{m}$

$376 \mathrm{f}_{\mathrm{FCC}}=0.1$ for an annealed sample during 1 hour at $1373 \mathrm{~K}$ ). The stabilized transformation

377 temperature after 30 cycles is clearly independent of the initial grain size.

$378 \quad$ 3.2. Allotropic transformation during mechanical deformation

379 3.2.1. Phase proportion evolution and work-hardening during tensile test 
The mechanical behavior in tension can be divided in three distinct stages. The first one

381 is the elastic part. Zhou et al. [28,29] have shown that this stage is characterized by a

382 kinking nonlinear elasticity resulting in fully reversible hysteresis induced by nucleated

383 dislocation loops in the slipping favored plane (the basal plane in the present case).

384 The second one, named stage A, characterizes the first work-hardening stage and appears

385 from a strain of 0.0045 up to 0.018 (Fig. 9). This stage is associated with a large reduction

386 of the work-hardening rate and is controlled by planar and single glide of basal

387 dislocations [9]. However the combination of basal slip and volume change during

388 transformation [26] does not satisfy von Mises criterion which requires, for a polycrystal,

389 five independent shear systems to undergo homogeneous strain without changes in

390 volume. In order to accommodate the plastic deformation and since the FCC to HCP

391 phase transformation is a low energy transformation requiring only simple shear, the

392 formation of martensitic phase can be considered as equivalent to the formation of twins.

393 Above a strain level of 0.018 , the slope of the work-hardening rate is lowered to an almost

394 constant value corresponding to stage B. This stage is described by twinning nucleation

395 and growth. Martinez et al. have shown that compression $\{10.1\}_{\mathrm{HCP}}$ and tensile $\{10.2\}_{\mathrm{HCP}}$

396 twins are the main twinning modes representing respectively $16 \%$ and $66 \%$ of total

397 observed twin planes [9].

398 Fig. 9 highlights the effect of these deformation mechanisms on the allotropic 399 transformation, for tensile sample strained along the rolling direction. The fast track FCC

400 phase proportion, determined from $\theta-2 \theta$ spectra achieved at $\left(\psi=0^{\circ}, \varphi^{\circ}=0^{\circ}\right)$, is plotted

401 (open triangles) versus the macroscopic applied true strain. This figure shows a 402 transformation of the initial residual FCC phase into HCP phase initiated by plasticity. 
403 From the beginning of stage A to the end of stage B, this transformation is done gradually

404 and linearly with the logarithm of the applied strain. In order to ensure reliability and 405 reproducibility of the experimental data, the tests were repeated three times by three 406 different investigators. The FCC phase proportion evolution during tensile loading can be 407 expressed by the following proposed straightforward equation:

$408 \quad$ FCC proportion $=\mathrm{a} * \log (\varepsilon)+\mathrm{b}$,

409 where coefficients are $a=-0.089 \pm 0.006$, and $b=0.017 \pm 0.01$, with a linear regression 410 coefficient $R^{2}=0.93$. In comparison, Sanderson found $a=-0.1$ and $b=0.019$ for

411 polycrystalline samples with $10 \mu \mathrm{m}$ grain size [6]. The experimental slope is similar in 412 stage A and in stage B, leading to the conclusion that the phase transformation does not 413 seem to be affected by the activation of twinning during stage B.

414 In order to take into account a doubtless evolution of the texture with the mechanical 415 loading and to study the anisotropy of the phase transformation, FCC phase proportion is 416 determined for each of the $(\psi, \varphi)$ couples covering a quarter of a pole figure $\left(0^{\circ}<\psi<\right.$ $41755^{\circ}, 0^{\circ}<\varphi<90^{\circ}$ ) using the 8 plane family couples detailed in Table 1 . Values are then 418 averaged and results are plotted (red solid circles named 1/4 PF) in Fig 9. Phase ratio 419 evolution shows the same tendency as the one determined at $\left(\psi=0^{\circ}, \varphi=0^{\circ}\right)$ for the two 420 plasticity stages, with the same slope but a $b$ - coefficient equal to $0.117 \pm 0.007$. However, 421 these averaged values are higher due to the influence of the texture on the phase 422 proportion quantitative determination. Calculations of the phase proportion taking into account the ODF (red open lozenges in Fig. 9) from complete recalculated PFs have been performed on the as-received material and on a specimen strained at 0.078 in order to confirm the relevance of the results obtained over a quarter of experimental PF under 
427 does not fundamentally change the results, the choice is made to simplify the 428 quantification of phase proportions at a single position (i.e. $\psi=0^{\circ}, \varphi=0^{\circ}$ ).
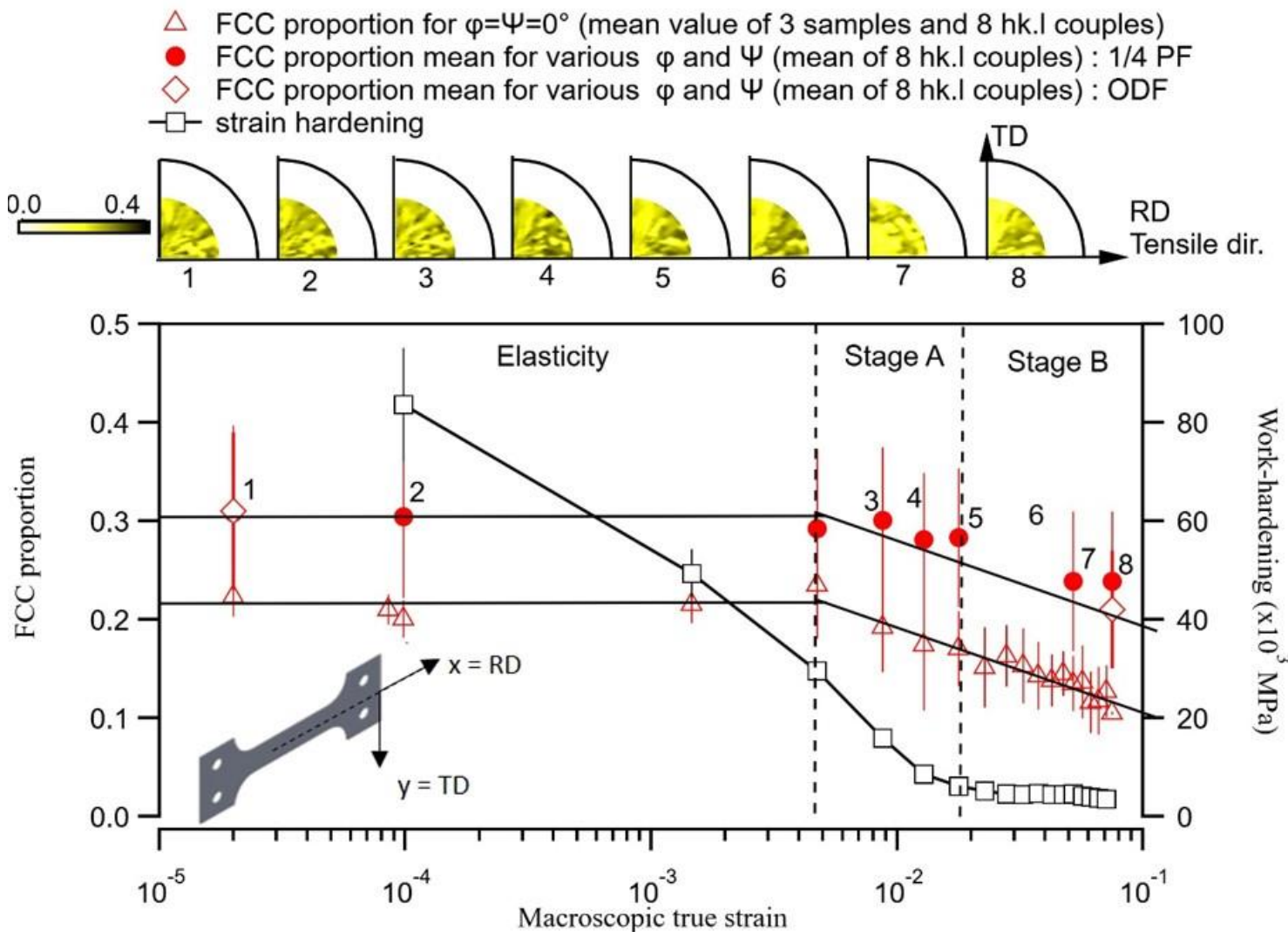

430 Figure 9: $\mathrm{FCC} \rightarrow \mathrm{HCP}$ transformation evolution as macroscopic strain increases. 431 Relationship between FCC phase proportion (red open triangle) and the deformation 432 stages illustrated by work-hardening (black open square). Monitoring of the phase 433 transformation anisotropy for various $(\varphi, \psi)$ orientations (maps) during tensile straining 434 with the corresponding average values (red solid circle). deformation mechanisms.

438 Deformation mechanisms and phase transformations can be explained by a 439 crystallographic analysis, comparing the different texture components observed on the 
440 recalculated PFs obtained thanks to XRD on a sample before and after straining. Fig. 10

441 shows $\{10.0\}_{\mathrm{HCP}},\{00.2\}_{\mathrm{HCP}},\{10.1\}_{\mathrm{HCP}},\{10.2\}_{\mathrm{HCP}},\{111\}_{\mathrm{FCC}}$ and $\{200\}_{\mathrm{FCC}}$ recalculated

442 PFs of the as-received sample and of a sample strained at $7.8 \%$ along RD. Except for the

443 habit plane between $\mathrm{HCP}$ and the retained FCC, it can be assumed that the initial state of

444 the HCP phase is not textured as compared to the deformed state that exhibits distinctive 445 poles which can be seen on the majority of PFs [30].
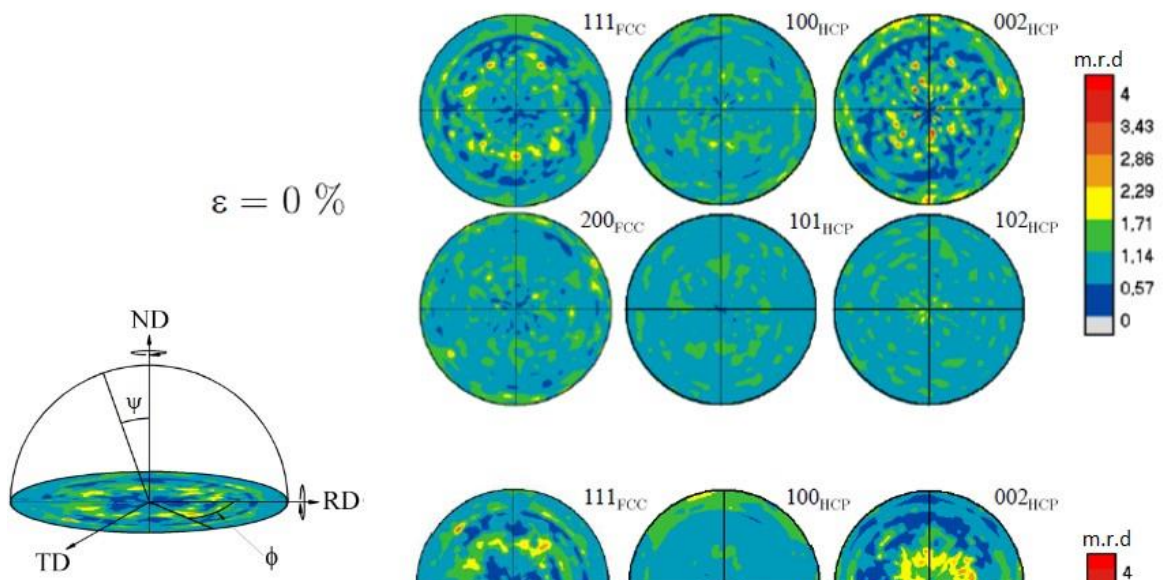

$\varepsilon=7,8 \%$

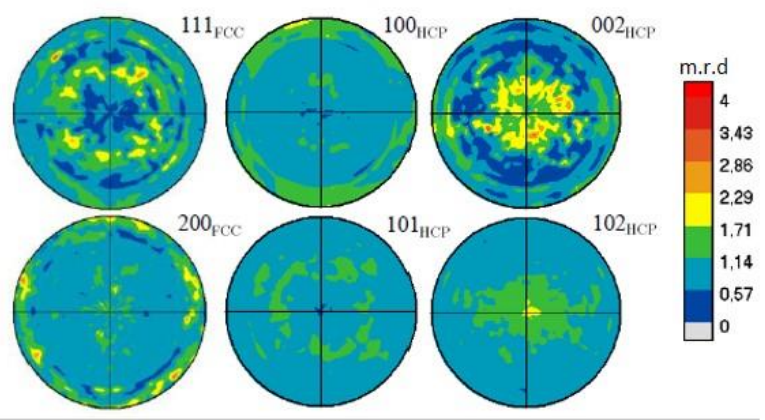

447 Figure 10: $\{10.0\}_{\mathrm{HCP}},\{00.2\}_{\mathrm{HCP}},\{10.1\}_{\mathrm{HCP}},\{10.2\}_{\mathrm{HCP}},\{111\}_{\mathrm{FCC}}$ and $\{200\}_{\mathrm{FCC}}$ 448 recalculated PFs of the as-received sample and of a sample strained at $7.8 \%$ along RD.

450 If the sample shows an isotropic orientation distribution in the initial state, three specific

451 orientation cases of the HCP lattice with respect to the loading direction are assumed to

452 be sufficient to study the orientation dependence of deformation mechanisms and phase

453 transformation: $c$-axis parallel, normal or inclined with respect to the loading direction, as shown in Table 3. 
Table 3: $\{00.2\}$ and $\{10.0\}$ PF reorientations peculiar to twinning systems and phase 456 transformation according to the 3 studied configurations.

\begin{tabular}{|c|c|c|c|c|}
\hline & $\begin{array}{c}\text { Twinning system } \\
{[31]}\end{array}$ & $\begin{array}{c}\text { Twinning shear } \\
{[32-34]}\end{array}$ & $\begin{array}{c}\boldsymbol{\psi} \text {-angle } \\
\text { reorientation on } \\
\{00.2\} \text { PF }\end{array}$ & $\begin{array}{c}\boldsymbol{\psi} \text {-angle } \\
\text { reorientation on } \\
\{\mathbf{1 0 . 0}\} \mathbf{P F}\end{array}$ \\
\hline $\begin{array}{c}\text { (a) Tension twin } \\
\boldsymbol{\sigma} / / \text {-axis }\end{array}$ & $\{10.2\}<10.1>$ & 0.13 & $5^{\circ}$ & $85^{\circ}$ \\
\hline $\begin{array}{c}\text { (b) Compression } \\
\text { twin } \\
\boldsymbol{\sigma} \perp \text { c-axis }\end{array}$ & $\{10.1\}<10.2>$ & 0.14 & $56^{\circ}$ & $34^{\circ}$ \\
\hline $\begin{array}{c}\text { (c) FCC-HCP } \\
\text { transformation }\end{array}$ & & & $43^{\circ}(111)$ & \\
$\boldsymbol{\sigma} / /(\mathbf{1 0 . 2})$ & & $66^{\circ}(11 \overline{1})$ & \\
\hline
\end{tabular}

458 As described in the 3.2.1 subsection, the plastic behavior of high-purity polycrystalline

459 cobalt exhibits two distinctive stages which correspond to the activity of basal slip (stage

460 A) and twinning deformation modes (stage B). The determination of Schmid's factor of

461 the basal plane for the three specific orientation cases $(\sigma / / c$-axis (a), $\sigma \perp c$-axis (b) and

$462 \sigma / /(10.2)(\mathrm{c}))$ shows that the unique configuration enabling such a slipping activity is (c):

463 (10.2) plane parallel to the specimen surface with a Schmid's factor close to 0.5 (most

464 suitable configuration for basal slip). Configurations (a) and (b) will then be the most

465 likely to show twin activity. Two types of twins have been frequently observed in

466 deformed high-purity polycrystalline cobalt [9,33]. The first one is the tensile twin

$467\{10.2\}<10.1>$, which activates when the HCP lattice undergoes a tensile strain along the

$468 c$-axis, because of the ratio $c / a<\sqrt{3}$ [32]. It represents $66 \%$ of the observed twinning 
470 compression twin $\{10.1\}<10.2>$, observed at a level of $16 \%$ and associated with a crystal 471 rotation of $56^{\circ}$.

472 In addition to the deformation mechanisms, strained cobalt also presents alse a phase 473 transformation FCC $\rightarrow \mathrm{HCP}$, which is diffusionless and occurs by dislocation gliding on 474 the habit plane $\{111\} / /\{00.2\}$, causing shear along the $[11 \overline{2}]_{\text {FCC }}$ direction (equivalent to 475 the HCP direction [11.0]). The phase transformation is called multi-variant due to its 476 capability to occur on several $\{111\}_{\mathrm{FCC}}$ planes, which display rotation angles of $70.53^{\circ}$ 477 between them [12] (illustrated in Fig. 11). However, due to the compactness difference 478 between the two phases, the resulting rotational angle after the phase transformation FCC $479 \rightarrow$ HCP becomes $71.4^{\circ}$ according to the orientation relationship established by Shoji480 Nishiyama [35]. Hence, the resulting crystal undergoes a theoretical volume change of 481 about $-0.3 \%$, which corresponds to a slight contraction along the c-axis $[26,36]$. This 482 phase transformation is more likely to be initiated when the habit plane $\{111\} / /\{00.2\}$ 483 shows an intermediary inclination as regard to the loading direction $[13,14]$ 484 corresponding to (c) configuration in Table 3. The crystallographic mechanism of FCC $485 \rightarrow$ HCP phase transformation is illustrated in Fig. 11, showing the FCC lattice atoms 486 displacement along the [112] direction and the formation of the HCP lattice from three $487\{111\}$ FCC planes. 


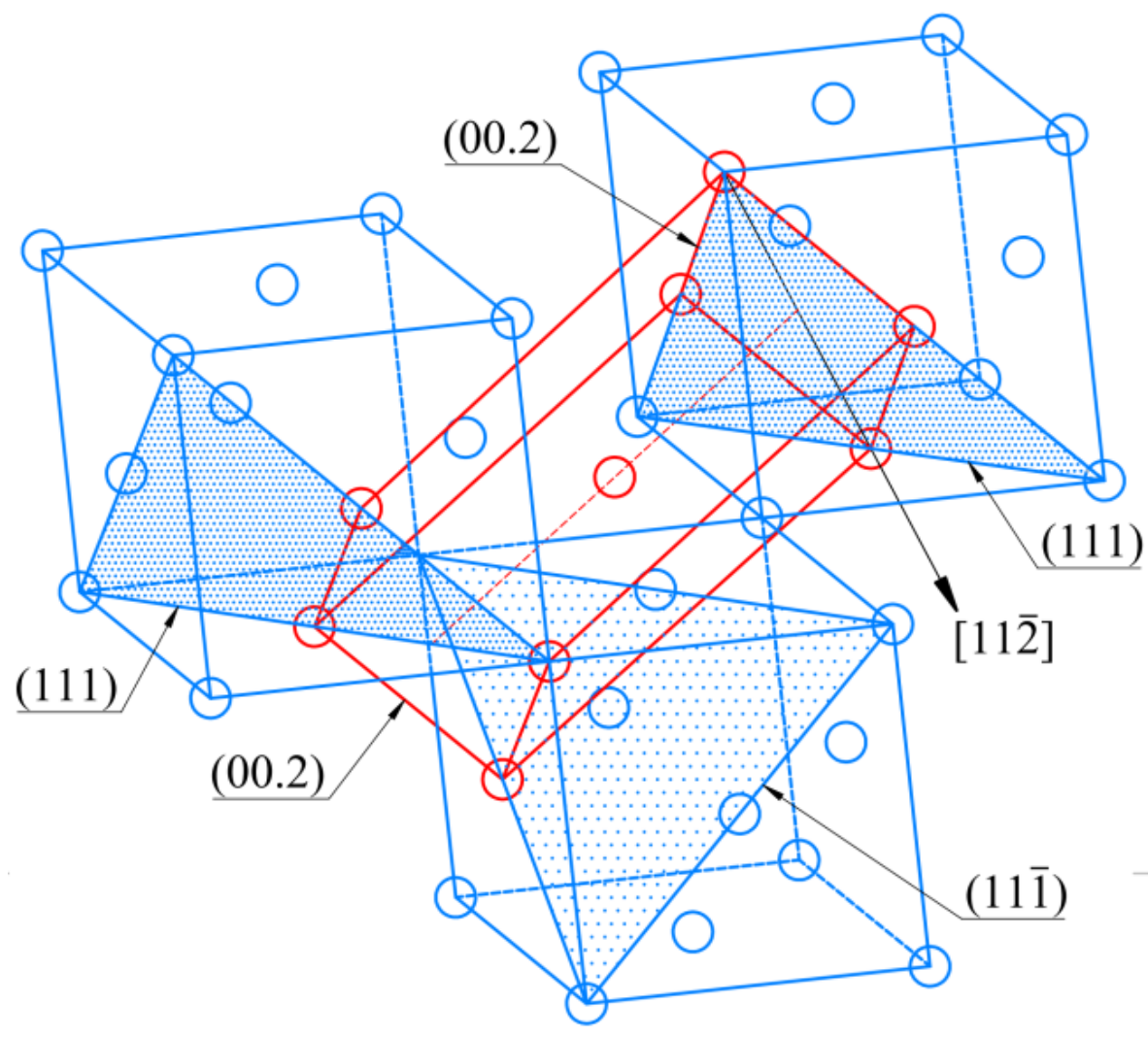

490 Figure 11: Schematic representation of the orientation relationship between the FCC 491 structure (in blue) and the HCP structure (in red) once shear has been achieved along the $492[11 \overline{2}]$ FCC direction.

494 The crystallographic analysis carried out on the PFs of the deformed sample highlights 495 the activated twin modes as well as the FCC $\rightarrow$ HCP phase transformation induced by 496 mechanical loading. It should be underlined that only two twin systems $(\{10.2\}<10.1>$ 497 for configuration (a) and $\{10.1\}<10.2>$ for configuration (b)) have been clearly identified 498 using the PFs of the sample loaded up to $7.8 \%$ strain. Those actually match the lowest 499 shear twinning values [32-34].

500 In the first configuration considered (a), the tensile twin mode $\{10.2\}<10.1>$ induces a 501 crystal reorientation of $85^{\circ}$. This configuration concerns the reorientation of $85^{\circ}$ of the $c$ 502 axis, which were initially parallel to the loading direction (displayed by the orange solid 
503 line lattice projection in Fig. 12 b) and become misaligned by $5^{\circ}$ as compared to the 504 normal of the sheet plane (ND) (displayed by orange dashed line lattice projection in Fig.

$505 \mathbf{1 2}$ b). For the twinned part, it results in an angle of $85^{\circ}$ between ND and the normal of 506 the twinned prismatic plane (10.0) and an angle of $5^{\circ}$ between ND and the normal of the 507 twinned basal plane (00.2). These crystallographic reorientations of the twinned region 508 as compared to the parent crystal is depicted by intensity reinforcement arcs on $\{00.2\}$ 509 and $\{10.0\}$ PFs at $5^{\circ}$ and $85^{\circ}$ (identified by dashed orange rings in Fig. 12 a), respectively.

510 On the $\{10.0\} \mathrm{PF}$, the orientation reinforcement is preferably done at $90^{\circ}$ from the loading 511 direction in the sheet plane (TD).

512 In the second configuration considered (b), the compression twin mode $\{10.1\}<10.2>$ 513 causes a crystal reorientation of $56^{\circ}$. Therefore, the resulting orientations of the twinned 514 basal plane (00.2) and twinned prismatic plane (10.0) to the sample surface are $56^{\circ}$ and $51534^{\circ}$, respectively (displayed by pink dashed line lattice projection in Fig. 12 b). These 516 crystallographic reorientations are highlighted by intensity reinforcement rings (dashed 517 pink rings in Fig. 12 a) that can be observed on $\{00.2\}$ and $\{10.0\}$ PFs at $56^{\circ}$ and $34^{\circ}$, 518 respectively. 
(a)
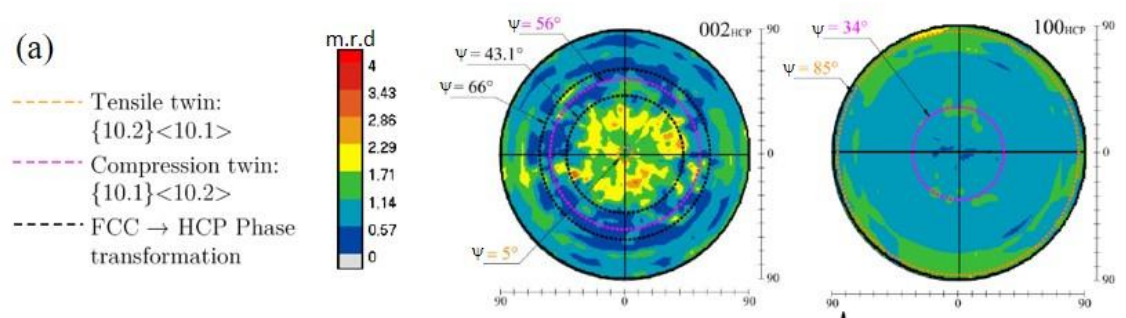

(b)

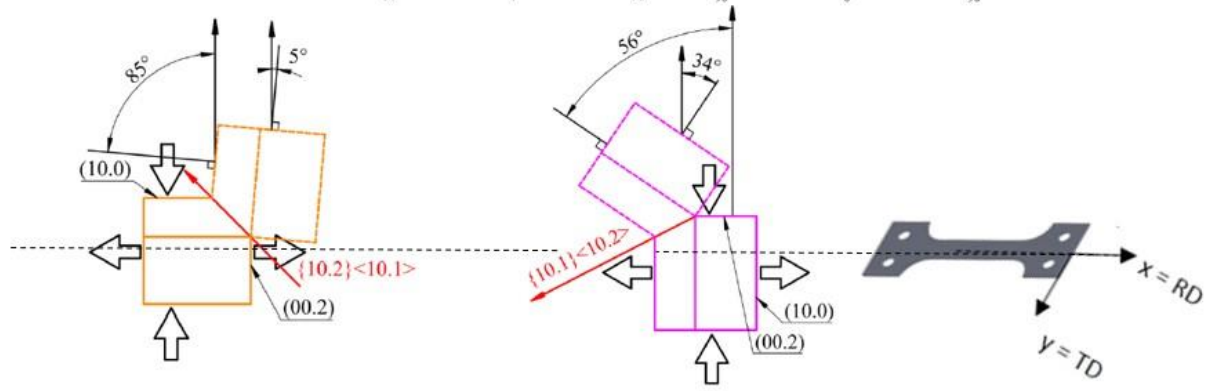

519

520 Figure 12: Identification of $\{10.2\}<10.1>$ tensile twinning system, $\{10.1\}<10.2>$ 521 compression twinning system and phase transformation on $\{00.2\}$ and $\{10.0\}$ PFs for the sample loaded up to $7.8 \%$ strain (a). Schematic representation of reorientations caused by the two twin systems (b).

In the third configuration considered (c): the FCC $\rightarrow$ HCP phase transformation induced by tensile straining can be observed on $\{10.2\},\{00.2\},\{111\}$ and $\{200\}$ PFs (dashed black circle in Fig. 12 a and Fig. 13 a). Because of the intermediate inclination of the

528 HCP lattice, the (10.2) HCP plane is parallel to the sheet plane. Thus, the ND matches the central pole (at $\psi=0^{\circ}$ ) observed on the $\{10.2\}$ PF. As described above, the FCC $\rightarrow$ HCP

530 phase transformation is multi-variant, and may occur on several $\{111\}$ FCC planes. For

531 this configuration and considering the Shoji-Nishiyama's relationship, the habit plane

$532(111) / /(00.2)$ is at an angle of $43.1^{\circ}$ to the sample surface and the $(11 \overline{1})$ one at an angle 533 of $66^{\circ}$, as illustrated on $\{00.2\}_{\mathrm{HCP}}$ and $\{111\}_{\mathrm{FCC}}$ PFs (dashed black circle in Fig. 12 a and

534 Fig. 13 a). Finally, the (200) FCC plane is oriented at $79^{\circ}$ to the ND and depicted by an 535 intensity reinforcement located at this $\psi$ value on the $\{200\}_{\mathrm{FCC}} \mathrm{PF}$. 
(a)
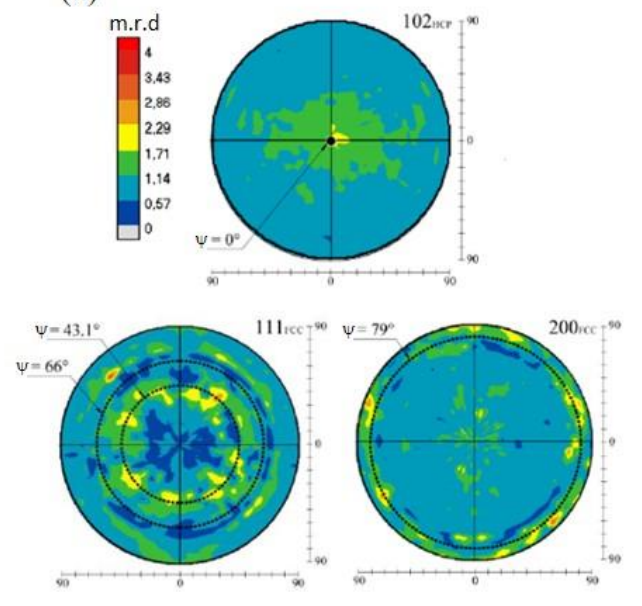

(b)

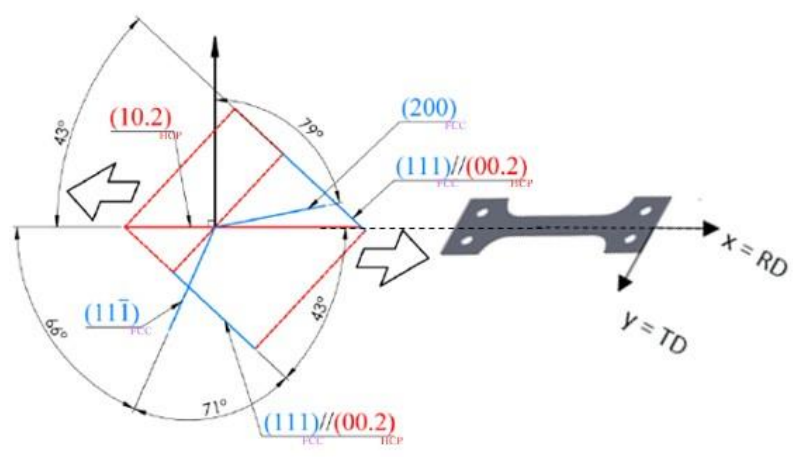

537 Figure 13: Identification of the phase transformation from $\{10.2\}_{\mathrm{HCP}},\{111\}_{\mathrm{FCC}}$ and $538\{200\}_{\text {FCC }}$ PFs for the sample loaded up to $7.8 \%$ (a). Schematic representation of 539 misorientations caused by the phase transformation (b).

541 Another way to analyze the evolution of the FCC $\rightarrow$ HCP phase transformation with the

542 mechanical loading as well as the evolution of the main tensile twin deformation mode

$543(\{10.2\}<10.1>)$ is to follow the integrated intensities of the peaks reflecting these two

544 phenomena. Fig. 14 shows the tracking of the integrated intensities of $\{00.2\}$ and $\{10.2\}$

545 peaks during straining (for $\psi$ respectively close to $5^{\circ}$ and $0^{\circ}$ ) which correspond,

546 respectively, to the activity of the twinning mode $\{10.2\}<10.1>$ and the FCC $\rightarrow$ HCP

547 phase transformation. It can be seen that the integrated intensity of the peak $\{00.2\}$

548 remains unchanged during straining until the beginning of stage B for which plasticity is

549 governed by twinning. Thereafter, the integrated intensity of the $\{00.2\}$ reflection linearly

550 increases with the macroscopic strain. The monitoring of the integrated intensity of the

$551\{10.2\}$ peak shows that the phase transformation, initiated by basal slip, starts at the

552 beginning of the plasticity, in agreement to the results obtained for the FCC volume

553 fraction evolution (see Fig. 9). Subsequently, the integrated intensity of the $\{10.2\}$ peak

554 increases with macroscopic strain until the end of stage A. At this strain level, the 
555 twinning mechanism is activated and becomes the main deformation mode, which causes

556 a lattice reorientation and a possible stress relaxation. Therefore, the slope of the

557 integrated intensity evolution of $\{10.2\}$ reflection tends towards 0 , and remains

558 unchanged with increasing macroscopic strain. Thus, at stage $\mathrm{B}$, the evolution of the

559 integrated intensity of the $\{10.2\}$ reflection seems to reflect a competition between the

560 phase transformation and the twinning process.

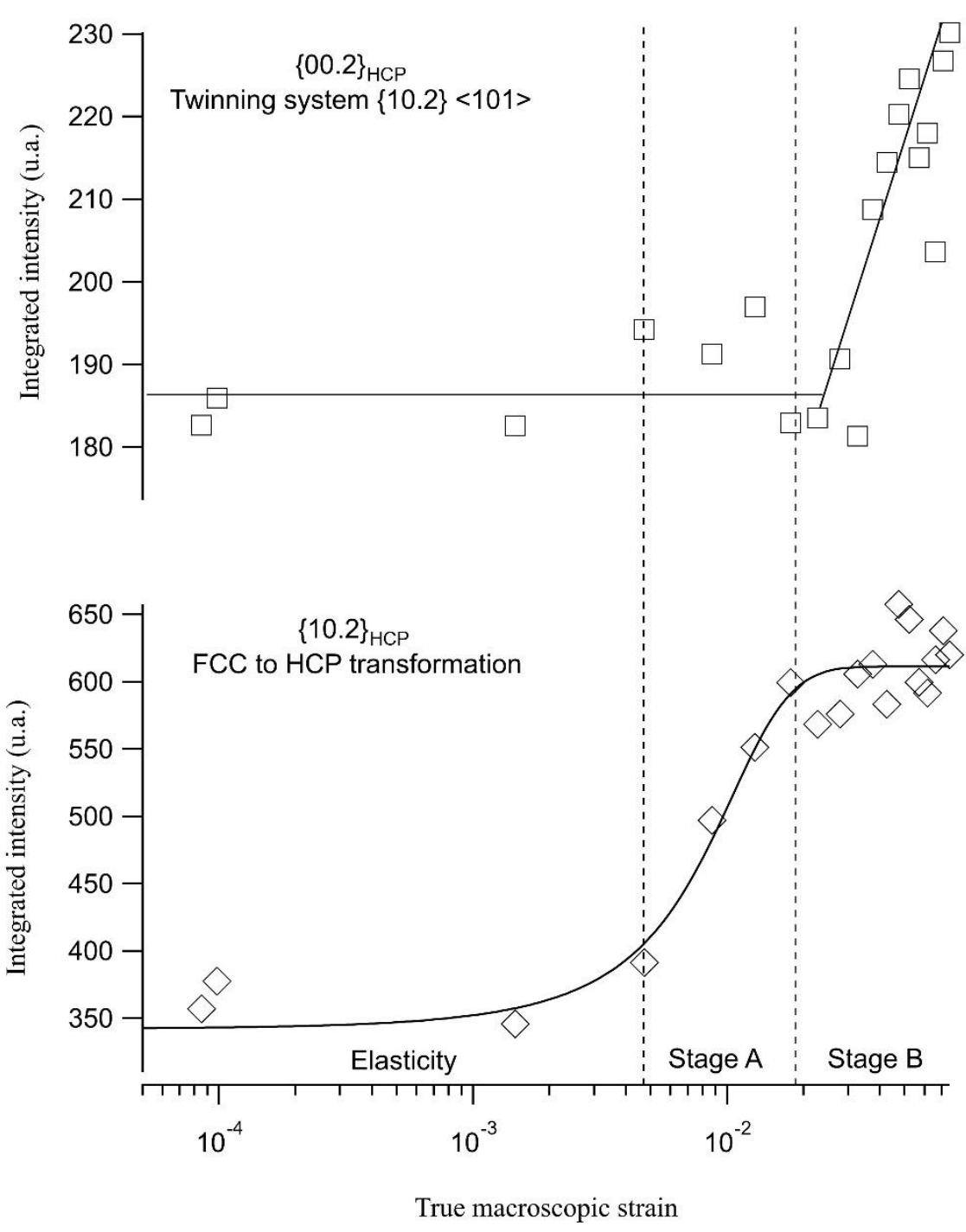

562 Figure 14: Evolution of the integrated peak intensity at $\psi=0^{\circ}$ for the $\{10.2\}$ reflection 563 and around $\psi=5^{\circ}$ for the $\{00.2\}$ reflection during a tensile test along the rolling direction. 
565 The monitoring of internal lattice strains (determined using the eq. (3)) of some $\{\mathrm{hkl}\}$

566 plane families of HCP and FCC phases during tensile tests is illustrated on Fig. 15. In

567 order to compare these results with those obtained during the cooling of the thermal cycle

568 (subsection 3.1.2), the internal lattice strains related to the two loading types (thermal and

569 mechanical) are thus superimposed while adapting the temperature range of the thermal

570 loading to the FCC $\rightarrow$ HCP phase transformation window so that it suits the stage A of

571 the tensile test, for which only the FCC $\rightarrow$ HCP phase transformation is occurring. As

572 can be seen in Fig. 15, this means that the slope of the curves macroscopic stress vs.

573 lattice strains (in grey) during the tensile loading in stage $\mathrm{A}$ is similar to the slope of the

574 curves temperature vs. lattice strains (in blue) obtained during cooling, except for the case

575 of the $\{10.2\}$ reflection, which exhibits a higher slope in stage A. For reminder the $\{00.2\}$

576 basal slip is the only deformation mode in this stage. It comes along with a phase

577 transformation which occurs in a plane shared by the two FCC and HCP crystallographic

578 structures (i.e. the habit plane). From the beginning of stage B, a deviation from this

579 linearity appears, leading to a lower evolution of the internal lattice strains with the

580 macroscopic stress. The main deformation mode in stage B is twinning (mostly $\{10.2\}$

581 type) which induces reorientations of the crystal lattice. Thus, a stress relaxation can be

582 generated within twinned grains and causes a lattice strain decrease. In this stage a

583 competition between twinning and phase transformation can therefore be highlighted.

584 The comparison between the internal lattice strain values at the beginning of stage B

585 shows that the $\{10.2\}$ family plane deforms elastically less than the others before

586 twinning. This result is consistent with the fact that, in the configuration (10.2) plane

587 parallel to the sheet plane (c), the deformation can be accommodated by basal slip before

588 that plasticity is controlled by twinning. 


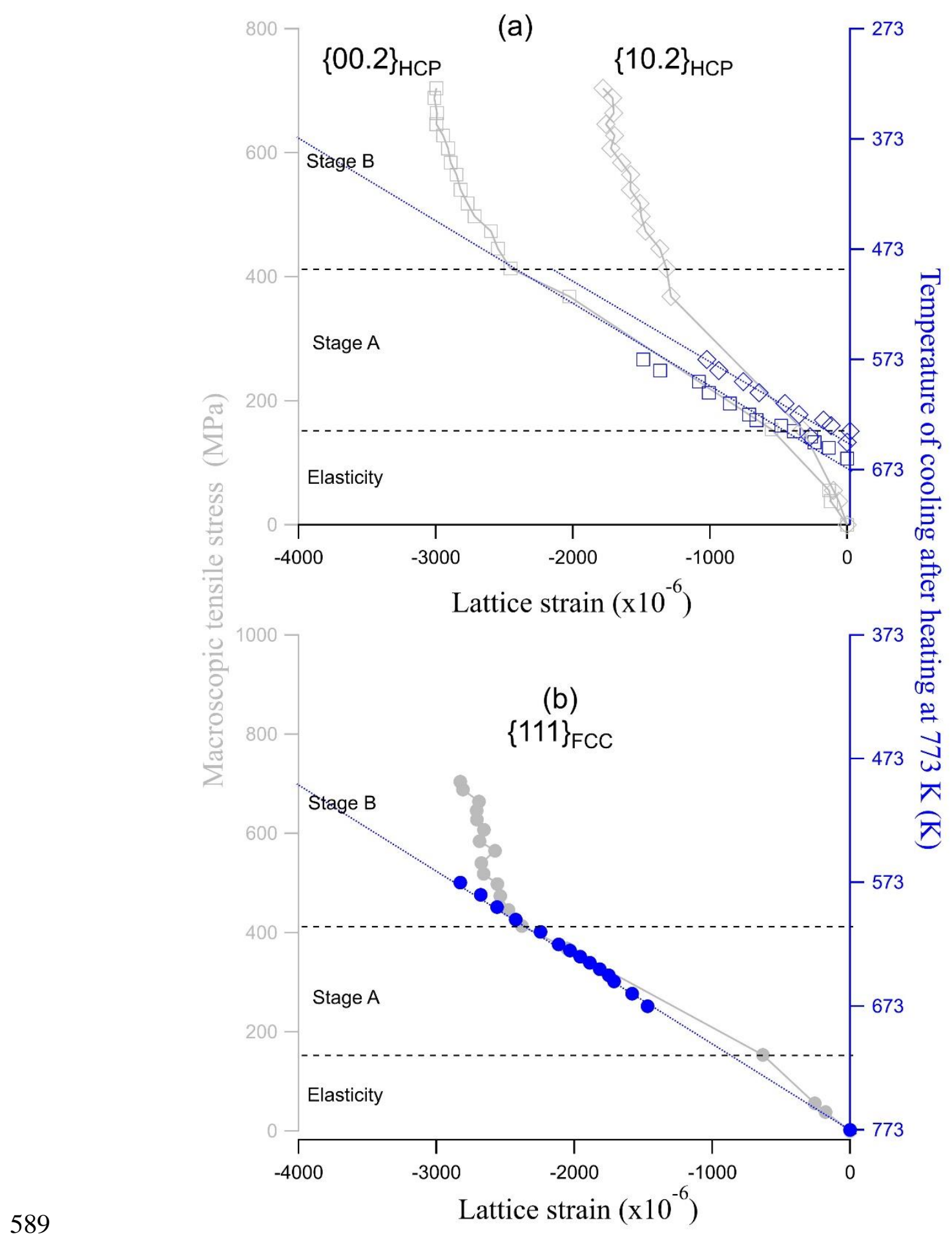

590 Figure 15: Example of lattice strains for $\{00.2\}_{\mathrm{HCP}}$ and $\{10.2\}_{\mathrm{HCP}}$ (a) and $\{111\}_{\mathrm{FCC}}$ (b) 591 reflections during a tensile test along the rolling direction (grey symbol) with those 592 measured during a cooling stage after a heating at $773 \mathrm{~K}$ (blue symbol). 


\section{4. Conclusions}

596 In the present work, new experimental results refresh and reinforce a scarce and dated to 597 1960's literature on phase transformations and strengthening mechanisms of 598 polycrystalline cobalt. The specific in situ temperature experiments have showed that the 599 FCC $\leftrightarrow$ HCP phase transformation displays a temperature hysteresis between heating and 600 cooling coupled to a macroscopic dilatometric hysteresis. However, the analysis of elastic 601 lattice strains during the transformation does not exhibit this phenomenon. 602 Complementary XRD studies of the phase transformation have highlighted the influence 603 of the initial microstructure. In this work, a new and original in situ XRD study under 604 mechanical loading has been performed revealing that the martensitic transformation of 605 the initial FCC residual phase can be induced by the plasticity and coupled with the strain606 hardening mechanisms. FCC to HCP transformation is activated by basal slip during the 607 work-hardening stage A and continues during stage B with a competition with the twin 608 mode.

609 
611 [1] G. Bouquet, B. Dubois: Scr. Metall., 1978, vol. 12, pp. 1079-1081.

612 [2] A.E. Ray, S.R. Smith, J.D. Scofielf: J. Phase Equilibria, 1991, vol. 12, pp. 644-

613648.

614 [3] G. Fleurier, E. Hug, M. Martinez, P.-A. Dubos, C. Keller: Philos. Mag. Lett., 2015, 615 vol. 95, pp. 122-130.

616 [4] H. Matsumoto: J. Alloys Compd., 1995, vol. 223, pp. L1-L3.

617 [5] H. Matsumoto: Phys. B Condens. Matter., 2003, vol. 334, pp. 112-117.

618 [6] C.R. Houska, B.L. Averbach, M. Cohen: Acta Metall., 1960, vol. 8, pp. 81-87.

619 [7] C.C. Sanderson: PhD Thesis, University of British Columbia, 1972.

620 [8] V.M. Marx, C. Kirchlechner, B. Breitbach, M.J. Cordill, D.M. Többens, T. Waitz,

621

622

623

624

625

626

627

628

629

630

631

632

633

634

635

636

637

638

639

640

641

642

643

644

645

646

647

648

649

650

651

652

653

654

655

656 G. Dehm: Acta Mater., 2016, vol. 121, pp. 227-233.

[9] M. Martinez, G. Fleurier, F. Chmelík, M. Knapek, B. Viguier, E. Hug: Mater. Charact., 2017, vol. 134, pp. 76-83.

[10] A. Seeger, H. Kronmüller, S. Mader, H. Träuble: Philos. Mag., 1960, vol. 6, pp. 639-655.

[11] G. Fleurier, M. Martinez, P.A. Dubos, E. Hug: Mater. Sci. Forum., 2017, vol. 879, pp. 560-565.

[12] J.W. Christian, W. Hume-Rothery: Proc. R. Soc. Lond. Ser. Math. Phys. Sci., 1951, vol. 206, pp. 51-64.

[13] H.T. Hesemann, P. Müllner, E. Arzt: Scr. Mater., 2001, vol. 44, pp. 25-30.

[14] H.T. Hesemann, P. Müllner, O. Kraft, D. Nowak, S.P. Baker, K. Finkelstein, E. Arzt: Scr. Mater., 2003, vol. 48, pp. 1129-1133.

[15] H.-R. Wenk, S. Matthies, J. Donovan, D. Chateigner: J. Appl. Crystallogr., 1998, vol. 31, pp. 262-269.

[16] N. Bruzy: PhD Thesis, Ecole Centrale de Nantes, 2018.

[17] N. Bruzy, M. Coret, B. Huneau, G. Kermouche, M. Mondon, E. Bertrand, L. Stainier: Exp. Mech., 2019, vol. 59, pp. 1145-1157.

[18] W.A. Rachinger: J. Sci. Instrum., 1948, vol. 25, pp. 254-255.

[19] M.J. Buerger: Proc. Natl. Acad. Sci., 1940, vol. 26, pp. 637-642.

[20] J.T. Bonarski, M. Wróbel, K. Pawlik: Mater. Sci. Technol., 2000, vol. 16, pp. 657662.

[21] W. Betteridge: Prog. Mater. Sci., 1980, vol. 24, pp. 51-142.

[22] K. Lonsdale, C. H. MacGillavry, G D. Rieck: International Tables for X-Ray Crystallography, Kynoch Press, 1962, vol 3.

[23] R. Bauer, E.A. Jaegle, W. Baumann, E.J. Mittemeijer: Philos. Mag., 2010, vol. 91, pp. 437-457.

[24] D. Gloaguen, B. Girault, B. Courant, P.-A. Dubos, M.-J. Moya, F. Edy, J. Rebelo Kornmeier: Metall. Mater. Trans. A., 2020, vol. 51, pp. 951-961.

[25] H. Bibring, F. Sebilleau: Rev. Métallurgie., 1955, vol. 52, pp. 569-578.

[26] G.W. Greenwood, R.H. Johnson: Proc. R. Soc. Lond. Ser. Math. Phys. Sci., 1965, vol. 283, pp. 403-422.

[27] G. Fleurier: PhD Thesis, Université de Caen, 2016.

[28] A. Zhou: PhD Thesis, Drexel University, 2008.

[29] A.G. Zhou, D. Brown, S. Vogel, O. Yeheskel, M.W. Barsoum: Mater. Sci. Eng. A., 2010, vol. 527, pp. 4664-4673.

[30] Y.N. Wang, J.C. Huang: Mater. Chem. Phys., 2003, vol. 81, pp. 11-26. 
[31] J.W. Christian, S. Mahajan: Prog. Mater. Sci., 1995, vol. 39, pp. 1-157. [32] M.H. Yoo: Metall. Trans. A., 1981, vol. 12, pp. 409-418.

659 [33] M. Martinez, E. Hug: Materialia, 2019, vol. 7, pp. 100420.

660 [34] S. Vaidya, S. Mahajan, C.M. Preece: Metall. Trans. A., 1980, vol. 11, pp. 11396611150.

662 [35] Z. Nishiyama: Martensitic Transformation - 1st Edition, Academic Press, 1978.

663 [36] F. Sebilleau, H.Bibring: Inst. Met. Monogr., 1956, vol. 18, pp. 209-217.

664 
665

666

667

668

669

670

671

672

673

674

675

676

677

678

679

680

681

682

683

684

685

686

687

688

689

690

691

692

693

694

695

696

697

698

699

700

701

702

703

704

705

706

707

708

Figures captions:

Graphical abstract: Evolution of metastable cobalt FCC volume proportion during thermal cycle and mechanical loadings.

Figure 1: EBSD Image Quality (IQ) map and phase cartography of as-received cobalt microstructure.

Figure 2: Diffraction patterns for $\{111\} \mathrm{FCC}$ and $\{00.2\}_{\mathrm{HCP}}$ reflections during heating and cooling.

Figure 3: Volume fraction of FCC phase during heating (red circle) and cooling (blue square) of cobalt calculated from XRD data. Error bars are the standard deviation on the 8 couples of family planes.

Figure 4: Mechanical state during thermal cycle considering the different tracked plane families. (a) Lattice strain evolution during heating (red) and cooling (blue). (b)

Thermal expansion coefficients during heating (red open circle) and cooling (blue open circle) obtained from XRD results. (c) Measured residual lattice strains after (black solid circle) the thermal cycle.

Figure 5: Dilatometric curves according to $\varepsilon_{x x}, \varepsilon_{y y}$ and $\gamma_{x y}$ during the thermal cycle. (x corresponds for this experiment to the rolling direction).

Figure 6: Influence of annealing conditions (temperature for a time of $1 \mathrm{~h}$ (a) and time for a temperature of $1373^{\circ} \mathrm{K}(\mathrm{b})$ ) on grain size and retained FCC phase proportion evolution.

Figure 7: Thermal loading paths in DSC performed for as-received (a), $573 \mathrm{~K}$ (b), $673 \mathrm{~K}$ (c) and $773 \mathrm{~K}$ (d) annealed samples with corresponding austenitic (red) and martensitic (blue) transformation peak tracking.

Figure 8: Temperatures of $\mathrm{HCP} \rightarrow \mathrm{FCC}$ and $\mathrm{FCC} \rightarrow \mathrm{HCP}$ transformations as a function of the number of applied DSC cycles (up to 30 cycles) of as-received sample superposed with the result of $573 \mathrm{~K}, 673 \mathrm{~K}$ and $773 \mathrm{~K}$ annealed samples.

Figure 9: FCC $\rightarrow$ HCP transformation evolution as macroscopic strain increases. Relationship between FCC phase proportion (red open triangle) and the deformation stages illustrated by work-hardening (black open square). Monitoring of the phase transformation anisotropy for various $(\varphi, \psi)$ orientations (maps) during tensile straining with the corresponding average values (red solid circle).

Figure 10: $\{10.0\}_{\mathrm{HCP}},\{00.2\}_{\mathrm{HCP}},\{10.1\}_{\mathrm{HCP}},\{10.2\}_{\mathrm{HCP}},\{111\}_{\mathrm{FCC}}$ and $\{200\}_{\mathrm{FCC}}$ recalculated PFs of the as-received sample and of a sample strained at $7.8 \%$ along RD. 
709 Figure 11: Schematic representation of the orientation relationship between the FCC

710 structure (in blue) and the HCP structure (in red) once shear has been achieved along

711 the $[11 \overline{2}]$ FCC direction.

713 Figure 12: Identification of $\{10.2\}<10.1>$ tensile twinning system, $\{10.1\}<10.2>$

714 compression twinning system and phase transformation on $\{00.2\}$ and $\{10.0\}$ PFs for

715 the sample loaded up to $7.8 \%$ strain (a). Schematic representation of reorientations

716 caused by the two twin systems (b).

717

718 Figure 13: Identification of the phase transformation from $\{10.2\}_{\mathrm{HCP}},\{111\}_{\mathrm{FCC}}$ and

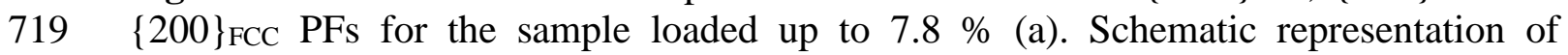
720 misorientations caused by the phase transformation (b).

Figure 14: Evolution of the integrated peak intensity at $\psi=0^{\circ}$ for the $\{10.2\}$ reflection and around $\psi=5^{\circ}$ for the $\{00.2\}$ reflection during a tensile test along the rolling direction.

Figure 15: Example of lattice strains for $\{00.2\}_{\mathrm{HCP}}$ and $\{10.2\}_{\mathrm{HCP}}$ (a) and $\{111\}_{\mathrm{FCC}}$ (b) 726 reflections during a tensile test along the rolling direction (grey symbol) with those measured during a cooling stage after a heating at $773 \mathrm{~K}$ (blue symbol). 
Tables captions:

Table 1: XRD reflections tracked for each experiment and the plane family couples used 733 for the phase volume fraction calculations.

Table 2: Applied temperatures for in situ XRD experiments during thermal cycle (heating rate $0.5 \mathrm{~K} / \mathrm{s}$ between each temperature step - $1 \mathrm{~h}$ acquisition duration for each

739 Table 3: $\{00.2\}$ and $\{10.0\}$ PF reorientations peculiar to twinning systems and phase transformation according to the 3 studied configurations. 